\title{
Molecular Signatures of Neuroinflammation Induced by $\alpha$ Synuclein Aggregates in Microglial Cells
}

OPEN ACCESS

Edited by:

Sermin Genc

Dokuz Eylul University, Turkey

Reviewed by:

Dean Louis Pountney,

Griffith University, Australia

Sonia George,

Van Andel Research Institute (VARI),

United States

*Correspondence:

Srikant Rangaraju srikant.rangaraju@emory.edu

Anumantha G. Kanthasamy

akanthas@iastate.edu

tThese authors have contributed equally to this work and share senior authorship

Specialty section: This article was submitted to Inflammation

a section of the journal

Frontiers in Immunology

Received: 15 October 2019 Accepted: 08 January 2020 Published: 31 January 2020

Citation:

Sarkar S, Dammer EB, Malovic E, Olsen AL, Raza SA, Gao T, Xiao H,

Oliver DL, Duong D, Joers V, Seyfried N, Huang M, Kukar T,

Tansey MG, Kanthasamy AG and

Rangaraju S (2020) Molecular

Signatures of Neuroinflammation Induced by aSynuclein Aggregates in Microglial Cells.

Front. Immunol. 11:33.

doi: 10.3389/fimmu.2020.00033

\author{
Souvarish Sarkar ${ }^{1,2}$, Eric B. Dammer ${ }^{3}$, Emir Malovic ${ }^{2}$, Abby L. Olsen ${ }^{4}$, Syed Ali Raza ${ }^{5}$, \\ Tianwen Gao ${ }^{5}$, Hailian Xiao ${ }^{5}$, Danielle L. Oliver ${ }^{6}$, Duc Duong $^{3}$, Valerie Joers ${ }^{6}$, \\ Nicholas Seyfried ${ }^{3,5}$, Meixiang Huang ${ }^{7}$, Thomas Kukar ${ }^{5,7}$, Malú G. Tansey ${ }^{6}$, \\ Anumantha G. Kanthasamy ${ }^{2 * \dagger}$ and Srikant Rangaraju ${ }^{5 * \dagger}$ \\ ${ }^{1}$ Department of Pathology, Brigham and Women's Hospital and Harvard Medical School, Boston, MA, United States, \\ ${ }^{2}$ Department of Biomedical Sciences, lowa State University, Ames, IA, United States, ${ }^{3}$ Department of Biochemistry, Emory \\ University, Atlanta, GA, United States, ${ }^{4}$ Department of Neurology, Brigham and Women's Hospital and Harvard Medical \\ School, Boston, MA, United States, ${ }^{5}$ Department of Neurology, Emory University, Atlanta, GA, United States, ${ }^{6}$ Department \\ of Neuroscience, University of Florida College of Medicine, Gainesville, FL, United States, ${ }^{7}$ Department of Pharmacology and \\ Chemical Biology, Emory University, Atlanta, GA, United States
}

Alpha-synuclein $\left(\alpha\right.$ Syn $\left._{\text {Agg }}\right)$ are pathological hallmarks of Parkinson's disease (PD) and other synucleinopathies that induce microglial activation and immune-mediated neurotoxicity, but the molecular mechanisms of $\alpha \mathrm{Syn}_{\mathrm{Agg}}$-induced immune activation are poorly defined. We performed quantitative proteomics by mass spectrometry coupled with PCR, immunohistochemical and functional validations studies to define the molecular characteristics of alpha synuclein mediated microglial activation. In mouse microglia, $\alpha S_{\text {Syn }}$ Agg induced robust pro-inflammatory activation (increased expression of 864 genes including Irg1, Ifit1, and Pyhin) and increased nuclear proteins involved in RNA synthesis, splicing, and anti-viral defense mechanisms. Conversely, $\alpha$ Syn $n_{\text {Agg }}$ decreased expression several proteins (including Cdc123, Sod1, and Grn), which were predominantly cytosolic and involved in metabolic, proteasomal and lysosomal mechanisms. Pathway analyses and confirmatory in vitro studies suggested that $\alpha \mathrm{Syn}_{\mathrm{Agg}}$ partly mediates its effects via Stat3 activation. As predicted by our proteomic findings, we verified that $\alpha \mathrm{Syn}_{\mathrm{Agg}}$ induces mitochondrial dysfunction in microglia. Twenty-six proteins differentially expressed by $\alpha$ Syn $_{\text {Agg }}$ were also identified as PD risk genes in genome-wide association studies (upregulated: Brd2, Clk1, Siglec1; down-regulated: Memo1, Arhgap18, Fyn, and Pgrn/Grn). We validated progranulin (PGRN) as a lysosomal PD-associated protein that is downregulated by $\alpha S_{\text {Syn }}$ Agg in microglia in-vivo and is expressed by microglia in post-mortem PD brain, congruent with our in vitro findings.

Conclusion: Together, proteomics approach both reveals novel molecular insights into aSyn-mediated neuroinflammation in PD and other synucleinopathies.

Keywords: synuclein, microglia, neuroinflammation, Parkinson's disease, proteomics 


\section{INTRODUCTION}

Chronic and sustained microglial activation is a key pathophysiological hallmark of multiple neurodegenerative disorders including Parkinson's disease (PD) (1). Neuroinflammation has been shown to be a key contributor to loss of dopaminergic neurons in animal models of PD $(2,3)$ and is also observed in striatal and cortical regions of the brain in post-mortem PD studies (4-8). A role for inflammation in PD was first suggested in 1988 when major histocompatibility complex molecules were shown to be upregulated in the brain of PD patients (4). Various pro-inflammatory factors like tumor necrosis factor $\alpha$ (TNF- $\alpha$ ) and interleukin $1 \beta$ (IL-1 $\beta$ ) have been shown to be upregulated in cerebrospinal fluid (CSF) and in different regions of the brain in PD patients (9). Moreover, in animal models of $\mathrm{PD}$, such as the 6-hydroxydopamine (6OHDA), 1-methyl-4-phenyl-1,2,3,6-tetrahydropyridine (MPTP), and rotenone models, selective loss of dopaminergic neurons is accompanied by chronic neuroinflammation (10-13). Human genome wide association studies (GWAS) have identified innate and adaptive immune genes as risk factors for PD $(14,15)$. Furthermore, treatment with non-steroidal anti-inflammatory drugs (NSAIDs), like ibuprofen, may be effective against PDrelated inflammation (16) suggesting that neuroinflammation may modify the course of neurodegeneration in PD.

Microglia, the innate immune responders of the CNS, are key mediators of neuroinflammation in neurodegenerative diseases (2). Depending on the stimuli or disease context, microglia can produce both anti-inflammatory and pro-inflammatory factors, reactive oxygen species (ROS), and growth factors. During development, microglia are also involved in pruning neuronal synapses (17-20), thereby tightly regulating neuronal physiology and survival (21). Pathological $\alpha$ Synuclein ( $\alpha$ Syn) aggregation in $\mathrm{PD}$ can induce microglial activation and dysfunction. One of the key pathological proteins involved in PD is $\alpha$ Synuclein ( $\alpha$ Syn) (22). Misfolded $\alpha$ Syn forms aggregates $\left(\alpha\right.$ Syn $\left._{\mathrm{Agg}}\right)$, which are the major constituents of Lewy bodies and Lewy neurites, both key neuropathological hallmarks of PD (23). $\alpha \operatorname{Syn}_{\text {Agg }}$ have been shown to strongly drive the microglial neuroinflammatory response in the diseased brain (22). $\alpha$ Syn $_{\text {Agg }}$ has been shown to be phagocytosed by microglia, leading to NADPH oxidase activation and ROS generation, in turn leading to the production of pro-inflammatory, neurotoxic cytokines and chemokines $(22,24,25)$. Recent studies have further shown that $\alpha \operatorname{Syn}_{\mathrm{Agg}}$ can bind to toll like receptor 2 and 4 (TLR2 and TLR4) and cluster of differentiation 36 (CD36) and thereby lead to receptor mediated activation of inflammatory signaling cascades $(26,27)$. Very recently, we demonstrated the $\alpha$ Syn $_{\text {Agg }}$ activates NLRP3 inflammasome through Fyn dependent signaling using cell culture, animal models and human tissues (28). Although $\alpha \operatorname{Syn}_{\mathrm{Agg}}$ have been shown to induce microglial activation, the integrated molecular pathways and signaling mechanisms involved have not been clearly delineated. A better understanding of the molecular and signaling mechanisms that drive chronic neuroinflammation in PD may provide mechanistic and therapeutically-relevant insights in PD and other $\alpha$ Synucleinopathies.
In this study, we have used quantitative proteomics by mass spectrometry to characterize the proteome-level alterations induced by $\alpha \operatorname{Syn}_{\mathrm{Agg}}$ in microglia, to identify potential molecular mechanisms of neuroinflammation in PD, including increased Stat3 signaling, increased mitochondrial dysfunction and ribosomal biogeneis and suppression of mitochondrial oxidative phosphorylation. By further comparing our results with existing microglial proteomic datasets, we have identified similarities between LPS- and $\alpha$ Syn $_{\mathrm{Agg}}$-induced microglial activation, as well as molecular mechanisms that are unique to $\alpha \operatorname{Syn}_{\mathrm{Agg}}$-induced microglial activation. To identify $\alpha S_{y n} n_{A g g}$-induced microglial protein alterations that are most relevant to human $\mathrm{PD}$, we cross-referenced $\alpha S_{y n} n_{\text {ggg }}$-regulated proteins in our data with PD risk genes previously identified in human GWAS studies and compared our proteomic results with transcriptomic data from human PD brain. Among the microglial proteins differentially regulated by $\alpha \operatorname{Syn}_{\mathrm{Agg}}$, we identified novel immune roles for PD-risk genes including progranulin (Grn) which appears to be downregulated in microglia in response to $\alpha \operatorname{Syn}_{\mathrm{Agg}}$. Collectively, these data reveal key molecular signatures of aSyn-induced microglial activation and highlight new disease mechanisms in microglia that may contribute to neurodegeneration in PD and other $\alpha$ Synucleinopathies.

\section{MATERIALS AND METHODS}

\section{Cell Culture and Treatments}

Primary microglial cells were isolated from postnatal mouse pups (P0-3) following our published protocol (29). Following isolation of microglia from mixed glial culture, cells were treated with $1 \mu \mathrm{M} \alpha$ Syn $_{\text {Agg }}$ for $24 \mathrm{~h}$.

Mouse microglial cell (MMC) line was a kind gift from Dr. Golenbock from University of Massachusetts (30). The MMC line was chosen over other microglial cell lines for proteomic studies due to its similarity with primary microglia as shown previously by our group (31). We have previously shown that MMC at basal level is in a relatively resting/quiescent state which becomes activated by LPS or $\alpha$ Syn $_{\text {Agg }}$ treatment to an M1-like state, similar to that seen in primary microglia. Due to the greater resemblance to primary microglia, the MMC line appears to be a better choice than the more commonly used immortalized microglia cell line, BV2 (32). MMC were grown in 10\% fetal bovine serum, DMEM, $1 \%$ penicillin/streptomycin and $1 \%$ glutamate. Treatments were performed in $2 \%$ FBS-containing media. Cells were treated with $1 \mu \mathrm{M} \alpha$ Syn $_{\text {Agg }}$ for $24 \mathrm{~h}$ (32).

\section{Recombinant Human $\alpha$ Synuclein Purification and Aggregation}

Recombinant $\alpha$ Syn was prepared following a previously published protocol $(19,33)$. Briefly, transformation with plasmid encoding human $\alpha$ Syn was performed in E. coli cells (BL21(DE3) strain) cells. Recombinant $\alpha$ Syn expression was induced by using isopropyl $\beta$-D-1-thiogalactopyranoside (IPTG) (Invitrogen). Cells were lysed and recombinant $\alpha$ Syn was purified as previously described $(34,35)$. We used FPLC system from Biorad to purify the protein and the FPLC chromatogram showed one peak suggesting the purity of the protein (Supplemental Figure 1A). 
Further, we performed Krypton stain (Supplemental Figure 1B) to determine the purity of the protein. For $\alpha$ Syn aggregation, recombinant protein solution was shaken at a speed of 1000 $\mathrm{rpm}$ at $37^{\circ} \mathrm{C}$ for 7 days (36). The level of endotoxin in $\alpha$ Syn preparations was quantified and $<5 \mathrm{EU}$ was detected. Moreover, we confirmed the conformation of the aggregates by electron microscopy (28).

\section{Animal Studies}

All animals were housed under standard conditions of constant temperature $\left(22 \pm 1^{\circ} \mathrm{C}\right.$ ), humidity (relative, $30 \%$ ), and a 12 -h light/dark cycle. Use of the animals and protocol procedures were approved by the Institutional Animal Care and Use Committee (IACUC) at Iowa State University (ISU), Ames, IA, USA. $\alpha$ Syn $_{\text {Agg }}$ pre-formed fibrils ( $\alpha$ Syn $n_{P F}$ ) were in injected in $\mathrm{C} 57 / \mathrm{BL}$ mice bred in our animal facility. Mice were anesthetized as previously described and then injected with 5 of $\mu \mathrm{g} \alpha \mathrm{Syn}_{\mathrm{PFF}}$ or vehicle. The coordinates indicating distance $(\mathrm{mm})$ from bregma were: AP 0.5 , ML 1.9, and DV 4 (28).

\section{Quantitative Proteomics of Mouse Microglia by Liquid Chromatography Coupled to Tandem Mass Spectrometry (LC-MS/MS)}

Samples were prepared essentially as described with slight modifications (37). MMCs were grown to $75 \%$ confluence, exposed to $\alpha \operatorname{Syn}_{\mathrm{Agg}}(1 \mu \mathrm{M})$ for $24 \mathrm{~h}$, and then harvested. Each cell pellet was individually homogenized in $300 \mu \mathrm{L}$ of urea lysis buffer (8 $\mathrm{M}$ urea, $100 \mathrm{mM} \mathrm{NaHPO}$, $\mathrm{pH} 8.5)$, including $3 \mu \mathrm{L}(100 \times$ stock) HALT protease and phosphatase inhibitor cocktail (Pierce) $(20,37)$. After lysis for $30 \mathrm{~min}$ at $4^{\circ} \mathrm{C}$, protein supernatants were transferred to $1.5-\mathrm{mL}$ Eppendorf tubes and sonicated (Sonic Dismembrator, Fisher Scientific) three times for $5 \mathrm{~s}$ with $15 \mathrm{~s}$ intervals of rest at $30 \%$ amplitude to disrupt nucleic acids and subsequently vortexed. Protein concentration was determined by the bicinchoninic acid (BCA) method, and samples were frozen in aliquots at $-80^{\circ} \mathrm{C}$. Protein homogenates $(100 \mu \mathrm{g})$ were diluted with $50 \mathrm{mM} \mathrm{NH} \mathrm{mCO}_{3}$ to a final concentration of $<2 \mathrm{M}$ urea and then treated with $1 \mathrm{mM}$ dithiothreitol (DTT) at $25^{\circ} \mathrm{C}$ for $30 \mathrm{~min}$, followed by $5 \mathrm{mM}$ iodoacetimide (IAA) at $25^{\circ} \mathrm{C}$ for $30 \mathrm{~min}$ in the dark. Protein was digested with 1:100 $(w / w)$ lysyl endopeptidase (Wako) at $25^{\circ} \mathrm{C}$ for $2 \mathrm{~h}$ and further digested overnight with 1:50 $(w / w)$ trypsin (Promega) at $25^{\circ} \mathrm{C}$. Resulting peptides were desalted with a Sep-Pak C18 column (Waters) and dried under vacuum. For LC-MS/MS analysis, derived peptides were re-suspended in $100 \mu \mathrm{L}$ of loading buffer ( $0.1 \%$ formic acid, $0.03 \%$ trifluoroacetic acid, $1 \%$ acetonitrile). Peptide mixtures $(2 \mu \mathrm{L})$ were separated on a self-packed C18 $(1.9 \mu \mathrm{m}$, Dr. Maisch, Germany) fused silica column $(25 \mathrm{~cm} \times$ $75 \mu \mathrm{M}$ internal diameter (ID); New Objective, Woburn, MA) by a Dionex Ultimate 3000 RSLCNano and monitored on a Fusion mass spectrometer (Thermo-Fisher Scientific, San Jose, $\mathrm{CA}$ ). Elution was performed over a $2 \mathrm{~h}$ gradient at a rate of 400 $\mathrm{nL} / \mathrm{min}$ with buffer $\mathrm{B}$ ranging from 3 to $80 \%$ (buffer A: $0.1 \%$ formic acid in water, buffer B: $0.1 \%$ formic acid in acetonitrile). The mass spectrometer cycle was programmed to collect at the top speed for 3 -s cycles. The MS scans (400-1,600 m/z range; 200,000 AGC; $50 \mathrm{~ms}$ maximum ion time) were collected at a resolution of 120,000 at $200 \mathrm{~m} / \mathrm{z}$ in profile mode, and the HCD MS/MS spectra $(0.7 \mathrm{~m} / \mathrm{z}$ isolation width; $30 \%$ collision energy; 10,000 AGC target; $35 \mathrm{~ms}$ maximum ion time) were detected in the ion trap. Dynamic exclusion was set to exclude previously sequenced precursor ions for $20 \mathrm{~s}$ within a $10 \mathrm{ppm}$ window. Precursor ions with +1 and +8 or higher charge states were excluded from sequencing.

Raw data files were analyzed using MaxQuant v1.6.3.4 with Thermo Foundation for RAW file reading capability, as previously published (20). The search engine Andromeda was used to build and search a concatenated target-decoy IPI/Uniprot mouse reference (downloaded Aug 14, 2015, with human alpha synuclein sequence added, Uniprot ID P37840). Protein methionine oxidation $(+15.9949 \mathrm{Da})$ and protein Nterminal acetylation $(+42.0106 \mathrm{Da})$ were variable modifications (up to five allowed per peptide); cysteine was assigned a fixed carbamidomethyl modification $(+57.0215 \mathrm{Da})$. Only fully tryptic peptides were considered with up to two miscleavages in the database search. A precursor mass tolerance of $\pm 20 \mathrm{ppm}$ was applied prior to mass accuracy calibration and $\pm 4.5 \mathrm{ppm}$ after internal MaxQuant calibration. Other search settings included a maximum peptide mass of $6000 \mathrm{Da}$, a minimum peptide length of six residues, and $0.05 \mathrm{Da}$ Tolerance for orbitrap (FTMS) HCD MS/MS scans. Co-fragmented peptide search was enabled to deconvolute multiplex spectra. The false discovery rate (FDR) for peptide spectral matches, proteins, and site decoy fraction were all set to $1 \%$. Quantification settings were as follows: re-quantify with a second peak finding attempt after protein identification has completed; match full MS1 peaks between runs; a 0.7min retention time match window was used after an alignment function was found with a $20 \mathrm{~min}$ RT search space. The labelfree quantitation (LFQ) algorithm in MaxQuant $(21,22)$ was used for protein quantitation. Data are available via ProteomeXchange with identifier PXD013691.

\section{qRT-PCR}

RNA isolation from primary microglial cells was performed as described previously $(38,39)$. Total RNA concentration was measured, and $1 \mu \mathrm{g}$ RNA was converted to cDNA using the Affinity Script qPCR cDNA synthesis system (Agilent Technologies). Real-time PCR was performed with the RT2 SYBR Green master mix (Thermo-Fisher \#K0172). The housekeeping gene 18s rRNA (Qiagen \#PPM57735E) was used as the reference for all qRT-PCR experiments. The $\Delta \Delta \mathrm{Ct}$ method was used, implementing the threshold cycle $(\mathrm{Ct})$ value for the housekeeping gene and for the respective gene of interest in each sample $(18,39)$. The primers were generated using primer bank $(40)$. The primers were synthesized at Iowa State DNA facility (see Table $\mathbf{1}$ for primer list).

\section{MAGMA of Human PD GWAS Studies}

To determine if any protein products of PD GWAS targets were enriched in a particular module, we used the single nucleotide polymorphism (SNP) summary statistics from http:// www.pdgene.org/ (15) to calculate the gene level association 
TABLE 1 | List of primers used in experiments.

\begin{tabular}{|c|c|c|}
\hline Gene & orward primer & everse primer \\
\hline co1 & CAGTCGAGGACAGCATTGG & GCTCCTTCGCCATGTTCTCA \\
\hline rd2 & AATGGCTTCTGTACCAGCTITAC & CTGGCTIITGGGATTGGACA \\
\hline ast & STGACCGATGTAGAC & ТСАССТСТТС \\
\hline Ik3 & TG & CTTGGA \\
\hline$n v k$ & AA & $A G$ \\
\hline carb2 & AGAAGGCGE & GA \\
\hline olga3 & AGACCTTCAGTTGTCCCTTGA & GCAGTGGAGCCTG \\
\hline amk2d & TCCAGAAGTCC & CCACCAC \\
\hline , & AGAGCTTGCTAGGAGTCAAAGA & TCTCTGCCA \\
\hline$n 1$ & GAG & TGTA \\
\hline iglec1 & CAGGGCATCCTCGACTGTC & GGAGCATCGTGAAGTTGGTTG \\
\hline$a m 175 b$ & САTCTCTACCGCCAACAATTCT & TGGCTAGTATTGCCTAGATTGGG \\
\hline lag/u & TATTACCAGAATGTGTG & GTGTGCAA \\
\hline Th & GCCATCGCGTCTGCTAAGAG & TGTTGATGATGCTTC \\
\hline Grn & ATGTGGGTCC & GCTCGTTATTCTAGG \\
\hline Tpp2 & TGTCAAAGACTGAGCTTGGAAAG & TGTTGGTGGAGGTATGAGATAGT \\
\hline tpa & GGAGGAGGTCATTCAGATTCTCG & CTCCCGACACTTCTGTATGGA \\
\hline ora & CGGCCCTCAGTCTACATTCC & ATGTCCTTTCGGATTTC \\
\hline a & XACAGACCT & GGATTGCCTCTCGTATTTCGT \\
\hline 9 & CATG & TCATCGTAGAATTTTGGCAGCTC \\
\hline Hspa1 & GCCAAACGGTTCATCGGGA & AGGTGCTATTACCAGCAAGGT \\
\hline spa1l & TCACGGTGCCAGCCTATTC & CGTGGGCTCATTGATTATTCTC \\
\hline Blnk & GCCCTCCAAGTGTTCCTCG & GGCAGGCATC \\
\hline$A r$ & $\mathrm{TC}$ & GAG \\
\hline Memo1 & GGATACACATACTGTGGGTCCT & CAGGGGCACATGATGGGAAG \\
\hline
\end{tabular}

value using MAGMA (15). MAGMA calculates the gene level association value by taking the mean of all the transformed (Z statistic) SNP P-values associated with a particular gene and uses a known approximation of the distribution to get the gene association value. MAGMA accounts for linkage disequilibrium (LD) using reference data with similar ancestry. These gene lists were further filtered to select for genes that have a MAGMA defined gene association value $>1.3$ (- $\log P$-value). For each module in the protein network, the mean GWAS significance value $(-\log \mathrm{P})$ was calculated as the enrichment score for the module. Random sampling (10,000 times) of the MAGMA gene list was used to assess the significance of the module enrichment score. The enrichment scores were then scaled by subtracting the mean and dividing by the standard deviation of the random samplings. The $P$-value was calculated as the proportion of samplings that have a scaled enrichment score greater than or equal to the module enrichment score. The psychiatric genomics consortium provides links to various data sets.

\section{Seahorse Mitostress Test}

Seahorse metabolic stress test was performed as described previously using a Xfe 24 Seahorse $(20,41)$. Briefly, primary microglial cells $(100,000$ per well) were plated in PDL-plated Seahorse 24 -well plate. Cells were treated with $\alpha \operatorname{Syn}_{\mathrm{Agg}}(1 \mu \mathrm{M})$ for $24 \mathrm{~h}$. For MitoStress test, $0.75 \mu \mathrm{M}$ oligomycin, $0.75 \mu \mathrm{M}$ FCCP and $0.5 \mu \mathrm{M}$ rotenone/antimycin were used. Wave 2.6.0 was used to analyze the data.

\section{Immunocytochemistry}

Immunocytochemical analysis was performed per previously published protocols (42). Briefly, primary microglia were isolated and plated on poly-D-lysine coated coverslips and treated. Following treatment, cells were fixed with $4 \%$ paraformaldehyde, and blocked with $2 \%$ BSA, $0.5 \%$ TritonX and $0.05 \%$ Tween. The cells were then incubated with primary antibody overnight, washed with PBS, incubated in secondary antibody. The following primary antibodies were used: STAT3 (Cell Signaling Technologies) and pSTAT3 (Y705) (Cell Signaling Technologies).

\section{Statistical and Bioinformatics Considerations}

Differential expression analyses of proteomic data were performed using pairwise $t$-test applied to log2-transformed expression data and adjusted for multiple comparisons using the Benjamini-Hochberg method. For comparisons across more than 2 groups, one-way ANOVA with Tukey post analysis was used. For 2 groups students $t$-test were performed using graphpad prism 5.0. Volcano plots were plotted with the ggplot2 package in R. Proteins with missing data were filtered for minimum criteria as described in results, and missing LFQ abundances were imputed according to an in-house implementation of the Perseus algorithm $(43,44)$ in R. Gene Ontology (GO) enrichment analyses were performed using GO-Elite software as previously described using input lists of differentially expressed proteins that were either increased or decreased following $\alpha \operatorname{Syn}_{\mathrm{Agg}}$ exposure. Pathway analyses were also performed (Metacore, Thompson Reuters) as previously described (37).

\section{Immunohistochemistry Studies of Post-Mortem PD Brain \\ Tissue Preparation}

Post-mortem human brain tissue was obtained from the Emory Neuropathological Core ( 3 cases with PD and 3 non-disease agematched healthy controls). Immunohistochemical studies were performed on 5- $\mu \mathrm{m}$ paraffin-embedded substantia nigra pars compacta (SNPc) and prefrontal cortex (PFC) sections to detect PGRN and IBA1 (pan-microglial marker) immunoreactivity. Tissue sections were deparaffinized twice by xylene and then hydrated. Deparaffinized sections were then treated with $0.2 \%$ Triton-X in a $1 \mathrm{X}$ Phosphate Buffered Saline (PBS) solution ( $\mathrm{pH}$ 7.4) for $1 \mathrm{~h}$ at $37^{\circ} \mathrm{C}$.

\section{Antigen Retrieval}

Permeabilized sections were placed in glass slide racks and submerged in a Wheaton dish (Cole Parmer) that contained $250 \mathrm{~mL}$ of sodium citrate buffer $\left(85^{\circ} \mathrm{C}, \mathrm{pH} 4.5\right)$. Wheaton glass dish was then placed into a large Pyrex dish filled with $500 \mathrm{~mL}$ of deionized water $\left(85^{\circ} \mathrm{C}\right)$ that served as the water bath. Heat mediated antigen retrieval was done by heating slides in a $1450 \mathrm{~W}$ microwave (Emerson) for $13 \mathrm{~min}$ at $60 \%$ power. 


\section{Immunostaining}

Hydrogen peroxide (3\%) in $60 \%$ methanol was used to eliminate endogenous peroxidase activity. These sections were blocked with serum (Jackson ImmunoResearch) in $0.2 \%$ Triton-X in $1 \mathrm{X}$ PBS for $1 \mathrm{~h}$ at $37^{\circ} \mathrm{C}$. Sections were then incubated overnight at $4^{\circ} \mathrm{C}$ with anti-progranulin antibody $(\mathrm{R} \& \mathrm{D}$ Systems; AF2420; 1:400) or anti-IBA1 (Wako; 019-19741; 1:500). Appropriate biotinylated secondary antibodies (Vector Labs) were then applied at 1:500 and incubated for $1 \mathrm{~h}$ at $37^{\circ} \mathrm{C}$. Staining was performed using the avidin-biotin (Vector Labs) complex method, and tissue developed for 15 min using 3,3'diaminobenzidine tablets (Sigma-Aldrich).

\section{Referenced Microglial Proteomic Datasets}

Previously published proteomic data from mouse microglia exposed to LPS were downloaded (37). Differentially expressed proteins in this dataset were compared to $\alpha$ Syn-induced proteomic changes in MMC. We also compared our results in mouse microglia to observations in a previously published transcriptomics study in human PD brain (45).

\section{RESULTS}

\section{Quantitative Proteomics of Mouse Microglia Reveals $\alpha$ Syn $_{\text {Agg }}$-Induced Neuroinflammatory Mechanisms}

We first performed qRT-PCR experiments showing that $\alpha \mathrm{Syn}_{\mathrm{Agg}}$ treatment induced the expression of M1-like pro-inflammatory markers by mouse microglia cell (MMC) line including Nos2, IL6 , TNF, and IL-1 $\beta$ without affecting or decreasing M2 markers such as IRF-4, IGF-1 and MRC1 (Supplemental Figure 2) suggesting that $\alpha S_{y n} n_{\mathrm{Agg}}$ induces a pro-inflammatory M1-like state in-vitro. Moreover, the increased expression of M1-like pro-inflammatory genes were seen only $\alpha \mathrm{Syn}_{\mathrm{Agg}}$ and not with $\alpha$ Syn monomers. Treatment with monomeric $\alpha$ Syn lead to no significant changes in expression of M1-like markers including Nos2, IL-6, TNF, and IL-1 $\beta$ (Supplemental Figure 3).

To identify proteomic changes in microglia in response to $\alpha \operatorname{Syn}_{\mathrm{Agg}}$, whole cell lysates of MMCs that had been exposed to $\alpha \mathrm{Syn}_{\mathrm{Agg}}$ were used for label-free mass spectrometry studies (6 biological replicates per group). MMC lysates in $8 \mathrm{M}$ urea buffer were enzymatically digested by trypsin and lysyl endopeptidase C, followed by LC-MS/MS, peptide identification and quantification. In total, we identified 35,725 total peptides (33,957 unique and razor assigned to proteomic database entries) that mapped to 3,816 unique mouse protein IDs and 3,738 unique mouse gene symbols. Of these, 3,345 proteins met inclusion criteria for further analysis (at least 3 non-missing values in either group or at least 2 non-missing values in one group if completely missing in the second group). Missing values in these included proteins were imputed using a R-based script designed to recapitulate the columnwise missing-value imputation algorithm of Perseus $(44,46,47)$ commonly applied to MaxQuant LFQ abundances (see Supplemental Table 1).
Differential expression analysis comparing $\alpha \mathrm{Syn}_{\mathrm{Agg}}$-treated with untreated MMCs identified 501 up-regulated and 749 downregulated proteins ( $T$-test unadjusted $p$-value $<0.05$ and at least 1.25-fold change in either direction, Figure 1A). Even after adjusting for multi-pairwise comparisons (BH FDR $<5 \%$ ), 1,578 proteins were differentially expressed of which 109 proteins demonstrated at least 4 -fold change in either direction (38 upregulated and 71 down-regulated, see Supplemental Table 1). The top $\alpha \operatorname{Syn}_{\mathrm{Agg}}$ up-regulated proteins included several proinflammatory proteins such as Irg1, Ifit1, and Pyhin1 while $\alpha S_{y n}{ }_{\text {Agg }}$-downregulated proteins included Sod1, Ahnak2, Cd93, and Thumpd1.

GO enrichment analyses of $\alpha \mathrm{Syn}_{\mathrm{Agg}}$-upregulated and downregulated proteins were then performed. Nuclear and nucleolar proteins involved in RNA binding and ribosomal biogenesis, RNA splicing and anti-viral defense responses were highly represented within the $\alpha S_{y n}{ }_{A g g}$-upregulated proteins (Figure 1B). KEGG pathways highly represented within these proteins included ribosome biogenesis, spliceosome, and fatty acid biosynthesis. Conversely, cytosolic proteins involved in oxidation-reduction and catabolic processes, proteasome core complex function and calcium binding were highly enriched within $\alpha S_{y n} n_{\mathrm{Agg}}$-downregulated proteins (Figure 1B). KEGG pathways enriched in this list included several small molecule metabolic pathways, as well as proteasome and lysosomal pathways. These results suggest that $\alpha \operatorname{Syn}_{\mathrm{Agg}}$ strongly induces RNA synthesis and splicing while suppressing homeostatic metabolic, mitochondrial, proteasomal, and lysosomal activities.

Canonical pathway analysis (Metacore) revealed that signaling via Stat3, Stat1, Oct3/4, and C/ebp transcriptional pathways are likely to be involved in $\alpha \mathrm{Syn}_{\mathrm{Agg}}$-mediated regulation of protein expression (Figure 2A). In confirmatory studies in primary microglia, we further observed that $\alpha \mathrm{Syn}_{\mathrm{Agg}}$ robustly increased both native Stat3 (Figure 2B) and Stat3 tyrosine phosphorylation (Y705) (Figure 2C). Further experiments with monomeric $\alpha$ Syn showed no increase in Stat3 (Supplemental Figure 4A) or pStat3 (Supplemental Figure 4B) protein expression indicating $\alpha \mathrm{Syn}_{\mathrm{Agg}}$-specificity of microglial responses. Together, we have identified probable pathways that regulate $\alpha \mathrm{Syn}_{\mathrm{Agg}}$-induced microglial activation and pro-inflammatory mechanisms.

\section{Identification of Proteomic Changes Unique to $\alpha$ Syn $_{\text {Agg }}$-Activated Microglia}

$\alpha$ Syn $_{\mathrm{Agg}}$, like LPS, may induce microglial pro-inflammatory activation via TLR signaling $(27,48,49)$ but in addition, may have unique effects on microglial activation via distinct mechanisms that are not completely understood. To identify $\alpha$ Syn $_{\mathrm{Agg}}$-induced microglial protein changes that overlap with, or are distinct from LPS pro-inflammatory activation of microglia, we compared $\alpha \mathrm{Syn}_{\mathrm{Agg}}$-induced differentially expressed proteins in this dataset with existing proteomic data from LPS-treated BV2 mouse microglia (37). 2,598 proteins quantified in our dataset were also quantified in this reference mouse microglial proteome comparing LPS-treated to untreated 

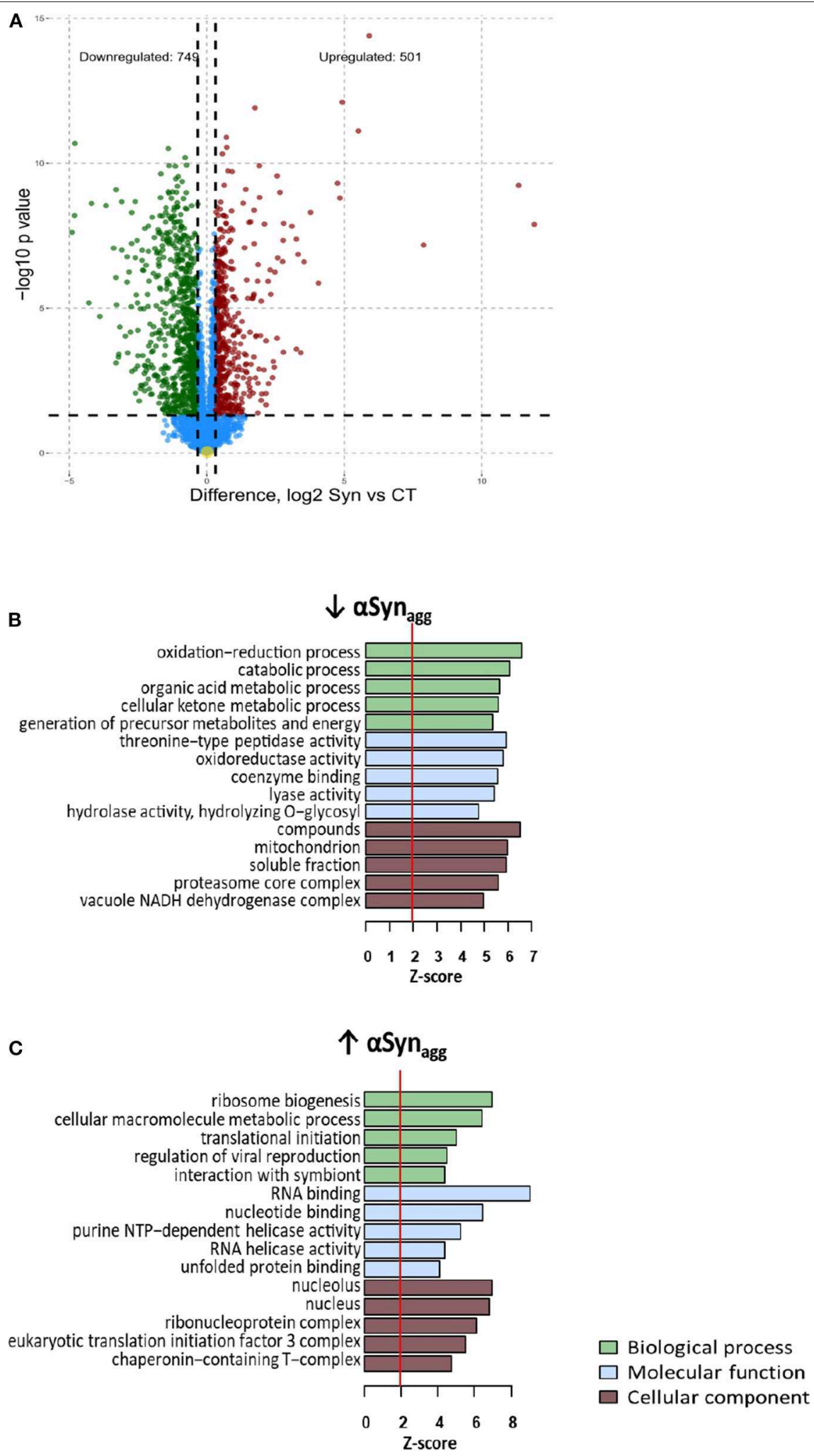

FIGURE 1 | Differential expression analysis of Synuclein-induced proteomic changes in microglia (A) Volcano plot: differential expression (Syn vs. Control) (B) Enrichment map: Gene ontology analysis of Syn-upregulated proteins (C) Enrichment map: Gene ontology analysis of Syn-downregulated proteins For b and c, Node color indicates direction of Syn-induced change in protein expression (Red: Upregulated, Blue: downregulated). Intensity of color of node represents level of significance (darker intensity indicates greater level of significance with white representing 0.05 significance level. Size of node indicates number of genes within the term (range 5-300). Edges connecting nodes are thinnest at a similarity score of 0.4 and max thickness at similarity max 1. 


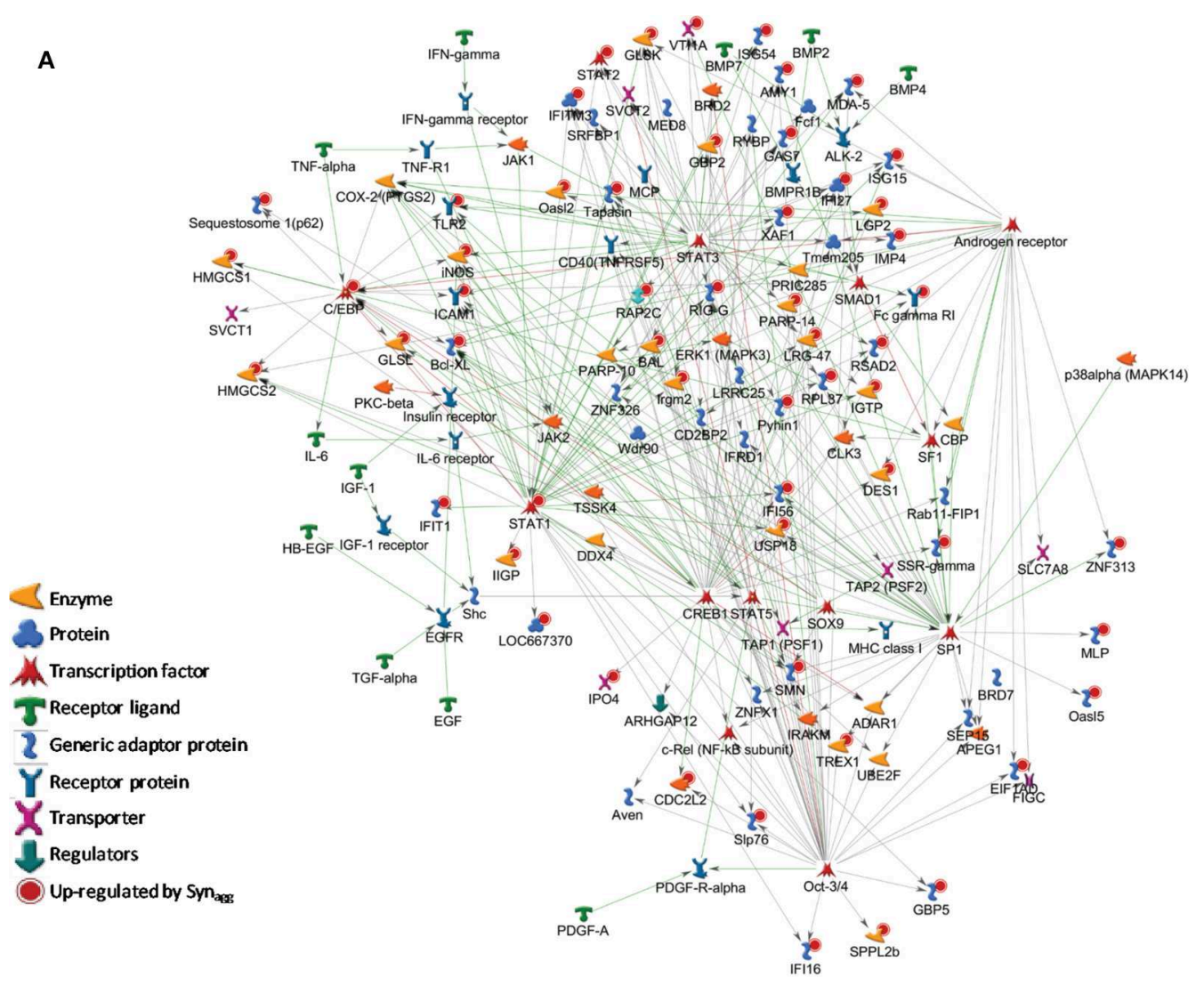

B
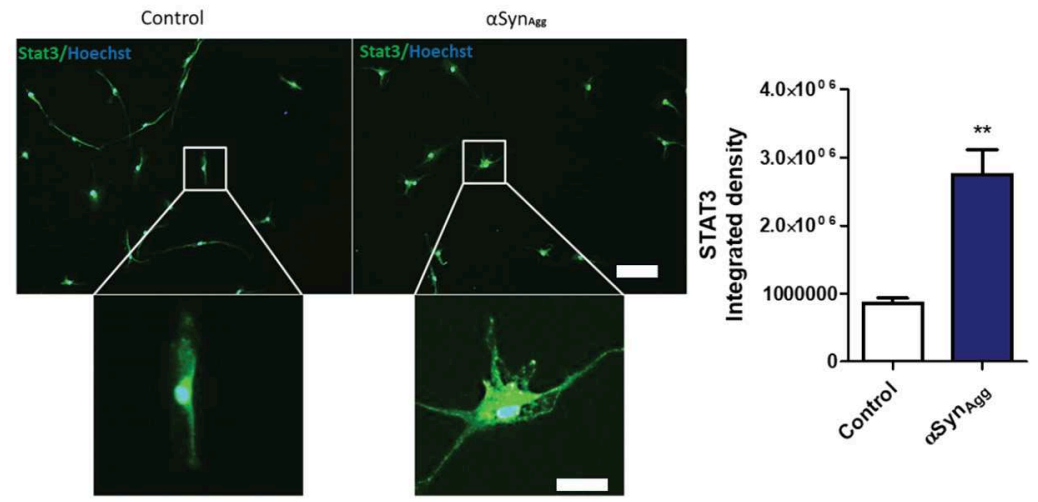

C
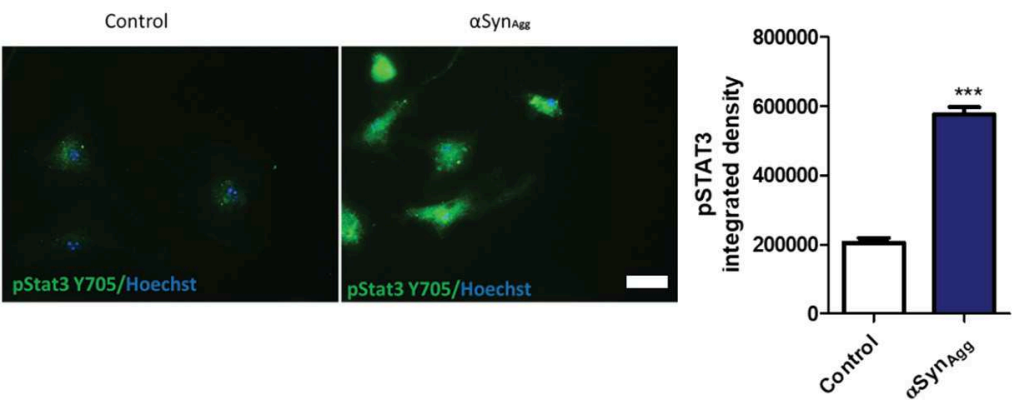

FIGURE 2 | Syn upregulated proteins are downstream of Stat3 and Stat1 signaling pathways. (A) Pathway analysis of the top three Syn-upregulated proteins in microglia. Key immune transcriptional factors including Stat3 and Stat1 are highlighted with Red circles. (B) Confirmation of Stat3 (Scale bar = $100 \mu \mathrm{M}$ inset scale bar $=15 \mu \mathrm{M})$ and (C) pSTAT3 upregulation by Syn in primary mouse microglia. Scale bar $=50 \mu \mathrm{M}$. Data analyzed using student's $t$-test with $n=4$ for each group. ${ }^{* *} p<0.01,{ }^{* \star *}<0.005$. 
BV2 microglia (Supplemental Table 2) (37). Among these shared proteins, 1,472 were differentially expressed by $\alpha \operatorname{Syn}_{\mathrm{Agg}}$ $(p<0.05)$ of which 233 proteins were differentially expressed in both LPS and $\alpha$ Syn $_{\mathrm{Agg}}$ datasets (unadjusted $p<0.05$ ), and overall level of concordance was low (Pearson's $R=0.18$ ) (Figure 3A). While majority of LPS-differentially expressed proteins $(67.9 \%)$ were also differentially expressed following $\alpha \operatorname{Syn}_{\mathrm{Agg}}$, only $15.8 \%$ of $\alpha \mathrm{Syn}_{\mathrm{Agg}}$-differentially expressed proteins were differentially expressed following LPS stimulation (Figure 3B). Among the shared proteins, the top concordant proteins included Irg1, Saa3, Sqstm1, Ehd1, Nadk, Icam1, and Marcksl1. These results indicate that while $\alpha \mathrm{Syn}_{\mathrm{Agg}}$ induces an LPS-like pro-inflammatory activation profile in microglia, the majority of $\alpha \mathrm{Syn}_{\mathrm{Agg}}$-induced changes are distinct from LPS-induced changes.

To define the unique molecular mechanisms regulated by $\alpha \operatorname{Syn}_{\mathrm{Agg}}$ that are distinct from LPS-induced changes, we performed an analysis restricted to 596 proteins that were only differentially regulated by $\alpha \operatorname{Syn}_{\mathrm{Agg}}$ but not by LPS (proteins with $\geq 1.25$-fold differential expression $[p<0.05$ ] in response to $\alpha \operatorname{Syn}_{\mathrm{Agg}}$, but $p>0.2$ for LPS vs. control comparisons) (Figure 3C). GO analysis of $216 \alpha \mathrm{Syn}_{\mathrm{Agg}}$-upregulated (but not by LPS) proteins revealed enrichment of nuclear and nucleolar proteins involved in RNA metabolic processes, ribonuclear biogenesis, and splicing (Figures 3D,E). On the other hand, $380 \alpha \mathrm{Syn}_{\mathrm{Agg}}$-specific and downregulated proteins (Figures 3F,G) were enriched for cytosolic, extracellular and exosomal proteins involved in proteasomal function, small molecular metabolism, peptidase activity, cellular catabolic processes, mTOR signaling and proteolysis. Overall, these comparative analyses show that while some microglial responses to $\alpha \operatorname{Syn}_{\mathrm{Agg}}$ are similar to pro-inflammatory effects of LPS, $\alpha \operatorname{Syn}_{\mathrm{Agg}}$ also uniquely increases the expression of ribonucleoprotein and the RNA binding machinery while suppressing catabolic and protein degradation/proteasomal processes in microglia.

\section{Identification of $\alpha \mathrm{Syn}_{\mathrm{Agg}}$-Regulated Proteins in Microglia That Have Pathophysiological Relevance to Human PD}

To derive a comprehensive list of known human PD risk genes identified by GWAS, we performed a meta-analysis of existing GWAS studies using MAGMA, and identified 622 genetic risk factors for PD (Supplemental Table 3) (15). We cross-referenced this list of PD risk genes with our microglia proteomic dataset and identified 28 proteins that were differentially expressed in microglia ( $\geq 2$-fold change in either direction) in response to $\alpha \operatorname{Syn}_{\mathrm{Agg}}$ that also met GWAS-level statistical significance (MAGMA $p$-value $<0.05$ ) (Figure 4A, Table 2). We then performed qRT-PCR studies (Table 3, Figure 4B) in primary murine microglia after exposure to $\alpha \mathrm{Syn}_{\mathrm{Agg}}$ using identical experimental conditions to determine whether findings observed in the MMC microglial cell line can be replicated in primary mouse microglia. Of the 26 transcripts evaluated, congruent changes were observed for 3 Syn-upregulated (Brd2, Clk3, Siglec1) and 11 Syndownregulated (Memo1, Arhgap18, Blnk, Fyn, Hspa1b, Isyna1, Itpa, Tpp2, Grn, Naglu, and Fam175b) proteins (Figure 4B, Table 3).

While most risk genes for PD regulate non-immune functions, genes/proteins that are most highly expressed in microglia are also most likely to regulate microglial functions and neuroinflammation in PD. Of 622 PD GWAS risk genes identified by MAGMA, 26 genes were most highly expressed in microglia based on a CNS cell-type-specific proteome from purified mouse microglia, astrocytes, oligodendrocytes and neurons (50). Of these microglial PD-risk genes, 5 proteins (Psmb9, Fam49b, Isyna1, Grn, and Naglu) were also differentially regulated by $\alpha \mathrm{Syn}_{\mathrm{Agg}}$ in our dataset (Figure 4A). Interestingly, these 5 proteins were all suppressed by $\alpha \operatorname{Syn}_{\mathrm{Agg}}$ by at least 2-fold, suggesting that polymorphisms in these 5 genes may partly replicate downstream immune effects of $\alpha S_{\text {Syn }}$ Agg. These $\alpha$ Syn $_{\mathrm{Agg}}$-regulated and human PD-risk proteins may represent immune genes with causative roles in $\mathrm{PD}$.

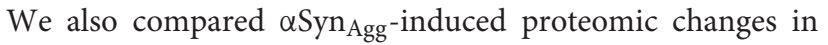
microglia with an existing gene microarray dataset obtained from the post-mortem samples from the substantia nigra regions of PD and non-PD control patients in which 5,933 genes were differentially expressed (45) of which, 782 gene symbols were also identified in our microglial proteomic dataset. 339 genes/proteins of these 782 demonstrated differential expression in response to $\alpha \operatorname{Syn}_{\text {Agg }}$ (Figure $4 \mathrm{C}$ ) although poor concordance between direction of change was observed (rho $=0.1$ ).

\section{Progranulin (PGRN) Protein Is Expressed by Microglia in Human PD}

We observed that PGRN protein levels as well as Grn mRNA transcripts were concordantly decreased in mouse primary microglia in response to $\alpha S_{y n} n_{A g g}$. Furthermore, Grn is highly expressed at the transcript and protein levels in mouse and human microglia $(50,51)$ in addition to being identified as a risk gene for PD (15). Therefore, we performed validation studies using an in-vivo model of aSyn-aggregate induced neuroinflammation in mice (36, 52). We analyzed brain tissues from mice that received stereotaxic injections with $\alpha$ Syn pre-formed fibrils ( $\alpha$ Syn $\left._{P F F}\right)$ (Supplemental Figure 5A). In this model, open-field versamax test revealed that $\alpha \mathrm{Syn}_{\mathrm{PFF}}$ induced motor behavioral changes in mice (Supplementary Figures 5B,C). Further, qPCR analysis of substantia nigra from the injected side validated Grn and other genes which were differentially regulated in our microglial proteomic dataset (Clk3, Golga3, Memo1, and Isyna1) (Supplemental Figure 5D). While these effects observed do not reflect microglia-specific alterations induced by $\alpha$ Syn, future studies will clarify the cell types responsible for these gene expression changes. Next, we determined patterns of PGRN protein expression in post-mortem brain tissues obtained from subjects with $\mathrm{PD}$ and age-matched non-disease controls, in SNpc and PFC regions (Figure 5). As expected, we observed the presence of Ibal+ microglia cells with ramified morphology in $\mathrm{PFC}$ in both $\mathrm{PD}$ and $\mathrm{HC}$ brains; 
A

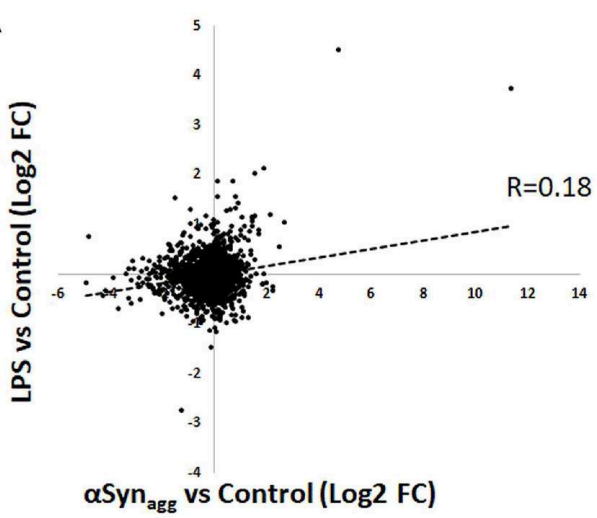

D

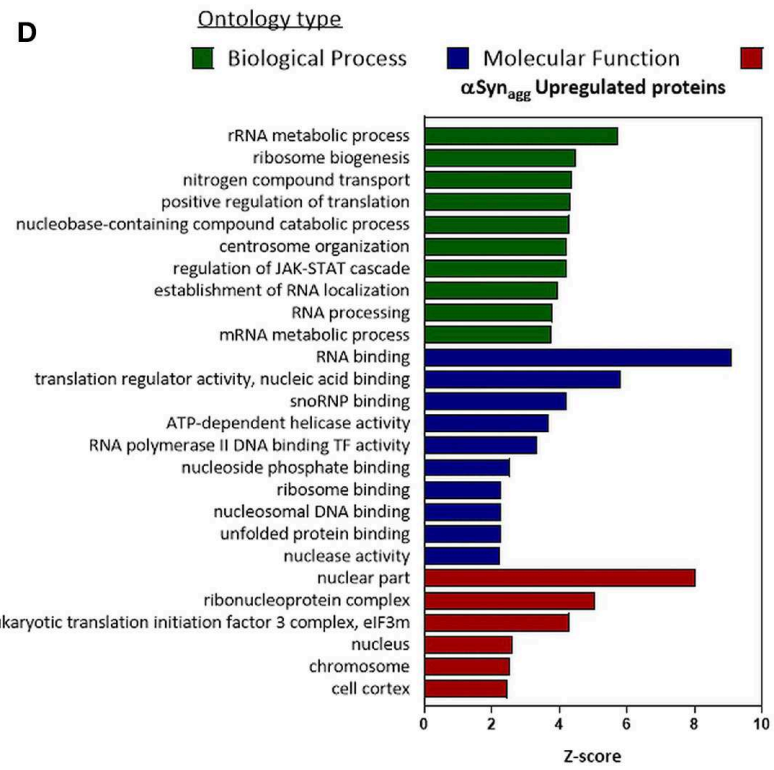

F

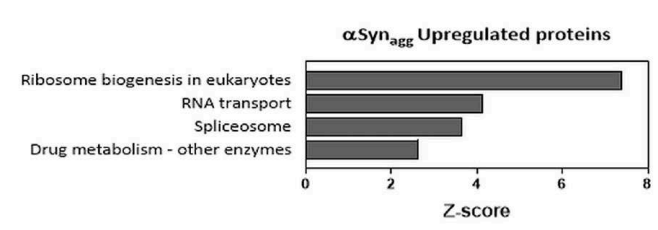

B

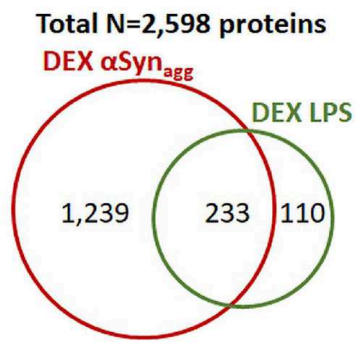

Cellular Component

Cellular Component

E

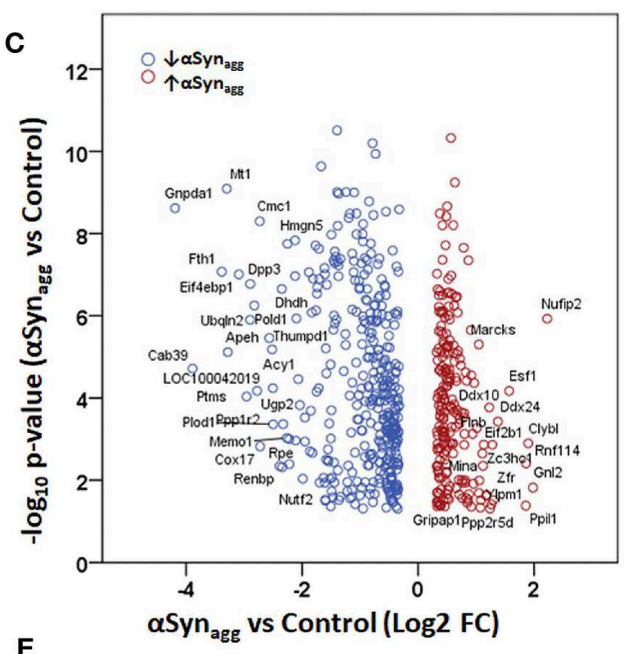

$\alpha S_{y n} n_{\text {agg }}$ Downregulated proteins

barbed-end actin filament capping protein catabolic proces response to testosterone negative regulation of leukocyte differentiation
lytic vacuole organization regulation of voltage-gated calcium channel activity
ryanodine-sensitive calcium-release channel activity amino sugar catabolic process
alcitity stress fiber assembly
-hydroxyproline metabolic proces threonine-type peptidase activity
hydrolyzing O-glycosyl compounds inositol phosphate phosphatase activity metallochaperone activity aminopeptidase activity metallopeptidase activity TBP-class protein bindin protein heterodimerization activity peptidase regulator activity peptidase regulator activity
proteasome core complex extracellular organelle BRISC complex BRCA1-A comple prefoldin complex uclear ubiquitin ligase complex cullin-RING ubiquitin ligase complex proteasome core complex, alpha-subunit complex

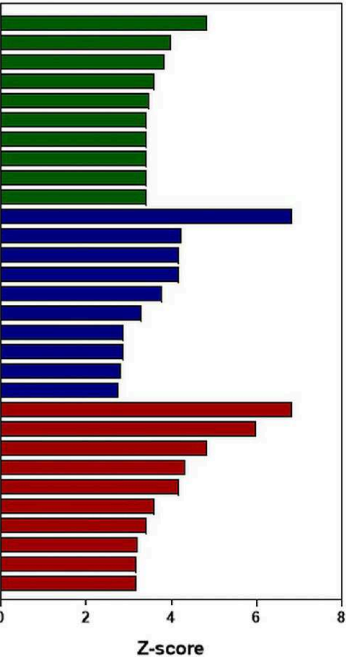

$\alpha S_{y n_{a g g}}$ Downregulated proteins

G

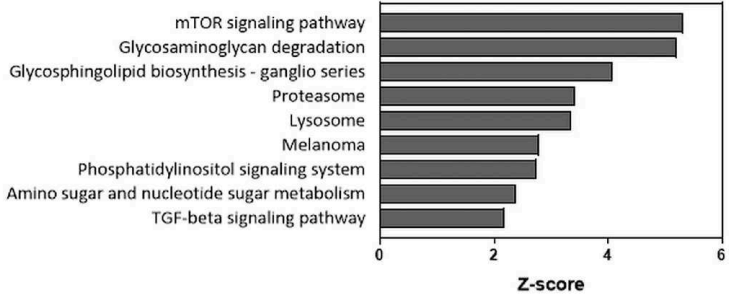

FIGURE 3 | Comparison of Syn-induced and LPS-induced microglial proteomic changes in mouse microglia. (A) Correlation between fold-changes in protein expression comparing $\alpha S_{\text {Agg }}$ vs. control with LPS vs. control microglial proteomic datasets. Pearson's Rho is shown. (B) Venn diagram showing degree of overlap between proteins differentially expressed (DEX) in response to $\alpha S_{\mathrm{Sy}} \mathrm{n}_{\mathrm{Agg}}$ and LPS in mouse microglia. (C) Volcano plot of proteins that are differentially expressed in response to $\alpha S y n_{\text {Agg }}$ but not by LPS (defined as at least 1.25 -fold change and $p<0.05$ in response to $\alpha S_{\text {Syn }}$ Agg but $p>0.2$ in response to LPS). The labeled proteins in the volcano plot are the significant hits. (D,E) Gene Ontology enrichment analyses of uniquely Syn-upregulated proteins in microglia (D: GO terms, E: KEGG pathways). (F,G) Gene Ontology analysis of uniquely Syn-downregulated proteins (F: GO terms, G: KEGG pathways). For panels d-g, only top 10 enriched GO or KEGG pathway terms that met significance criteria (enrichment Z-score>1.96) are shown.

whereas the PD SNpc displayed increased numbers of Iba1+ cells as compared to HC SNpc. PGRN immunoreactivity was predominantly observed in the melanized dopaminergic neurons in the SNpc, and to a lesser extent in cells with glial morphology in the SNpc. However, relative to $\mathrm{HC}$ $\mathrm{SNpc}$, PD SNpc displayed more PGRN+ inclusions and intense labeling in cells lining vessels which did not have glial morphology. Unlike the SNpc, PGRN immunoreactivity 
A

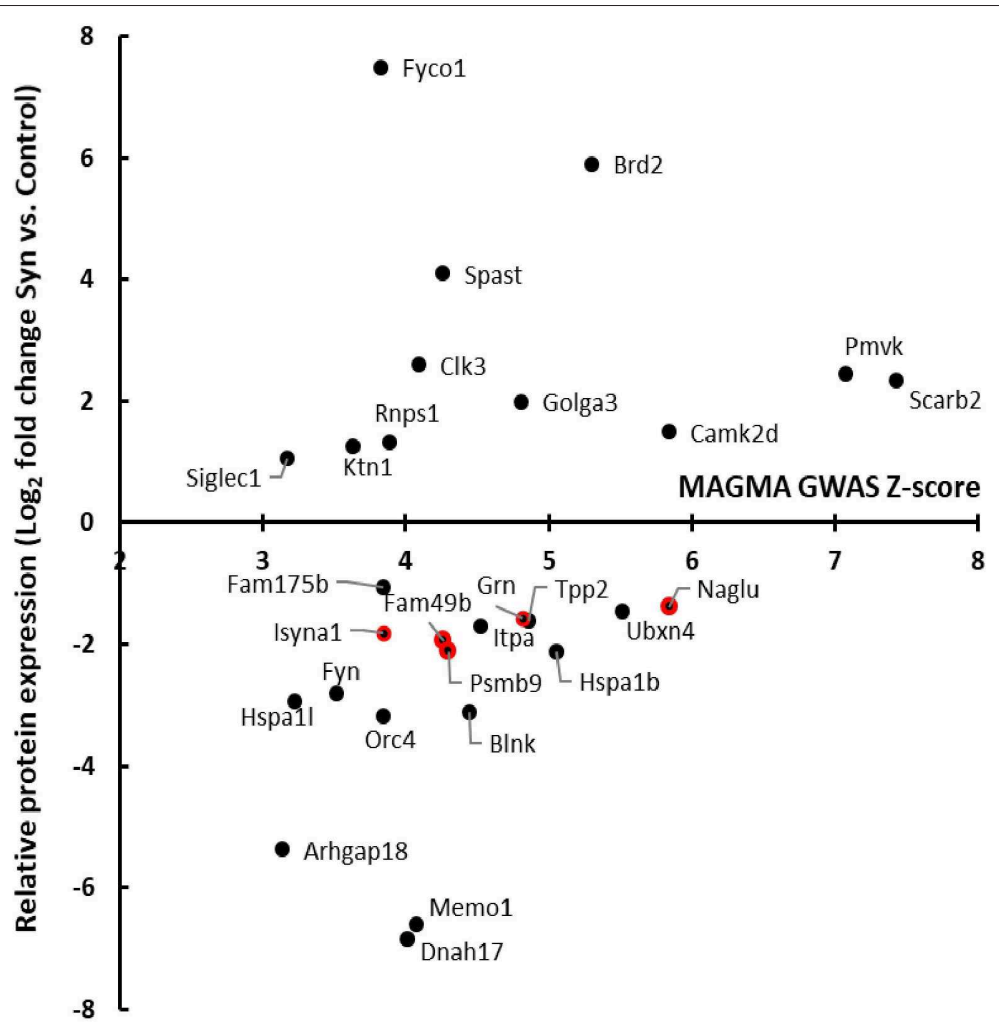

B

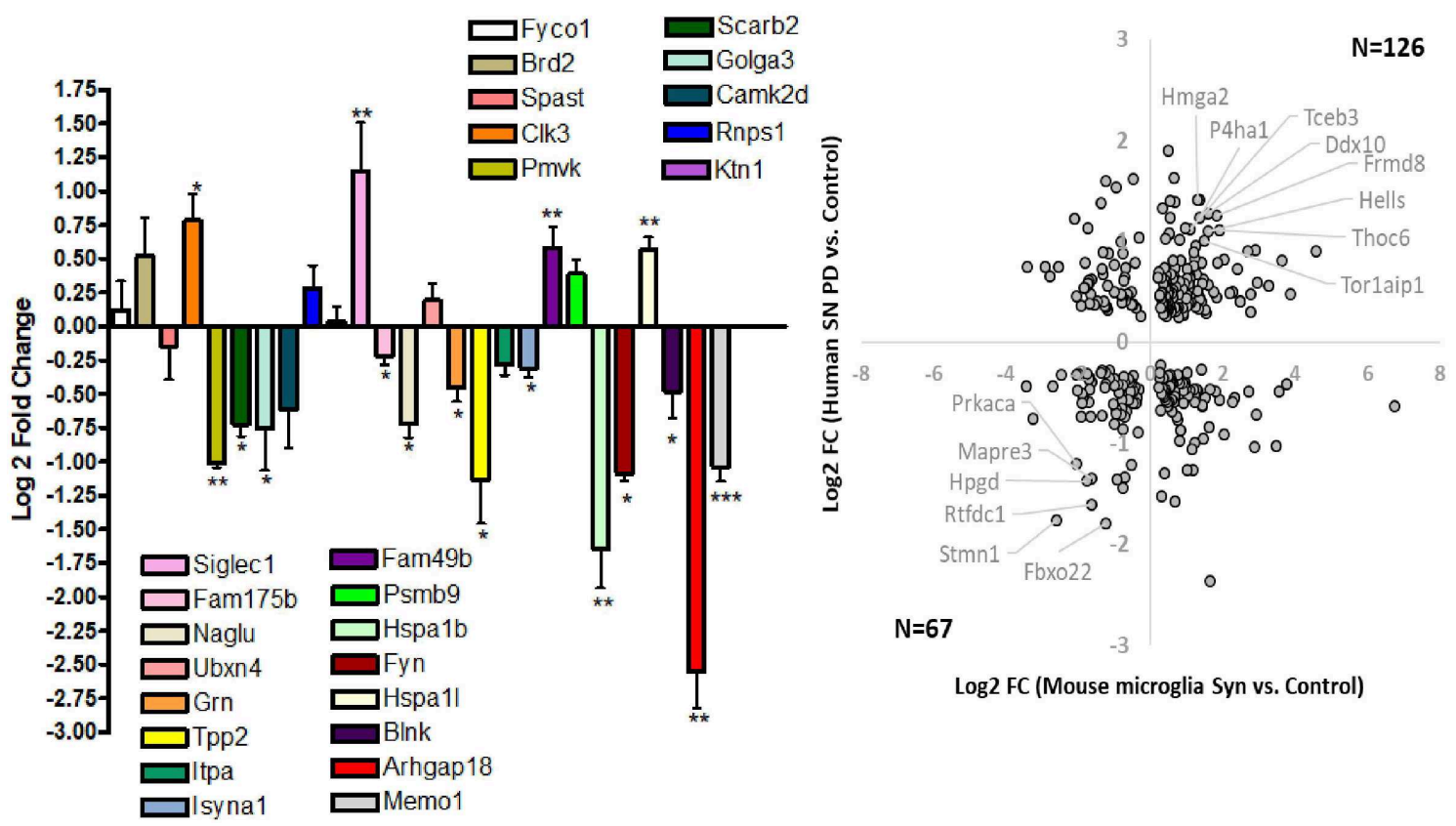

FIGURE 4 | Identification of Syn-induced microglial proteomic changes that are relevant to human PD pathogenesis. (A) MAGMA analysis of PD GWAS risk genes that are also differentially expressed in response to Syn. The 5 gene symbols highlighted in red represent proteins that are also most highly expressed in microglia as determined by CNS cell-type-specific proteomics. (B) qRT-PCR validation studies of human PD GWAS and Syn-regulated proteins in primary mouse microglia. (C) Comparison of results from MMC Syn vs. control proteomics dataset and PD vs. control substantia nigra microarray study. 39 gene symbols showed differential expression at the unadjusted $p<0.05$ level. Of these 193 (57\%) showed concordant changes in both datasets. Gene symbols meeting at 2-fold change in both datasets are highlighted ( 8 concordantly upregulated and 6 concordantly downregulated). 
TABLE 2 | PD risk genes demonstrating differential protein expression in microglia following $\alpha$ Syn Agg .

\begin{tabular}{|c|c|}
\hline Protein & Probable role \\
\hline FYCOI & Regulates Phagosome maturation \\
\hline BRD2 & $\begin{array}{l}\text { Inhibition of BRD2-4 (BET proteins) leads to decreased } \\
\text { inflammation through SIRT activation }\end{array}$ \\
\hline SPAST & $\begin{array}{l}\text { SPAST was significantly increased in prostate tissue with high } \\
\text { inflammation }\end{array}$ \\
\hline CLK3 & Splicing; CLK1 have been shown to be a target in AD \\
\hline PMVK & HFD promotes PMVK in CD44 positive cells \\
\hline SCARB2 & Involved in innate immunity and autophagosome maturation \\
\hline GOLGA3 & $\begin{array}{l}\text { GOLGA3 decreases ubiquitination of serine racemase. } \\
\text { D-serine increases oxidative stress and causes inflammation }\end{array}$ \\
\hline CAMK2D & Downstream of Nfkb \\
\hline RNPS1 & Involved in Nonsense mediated deacy \\
\hline KTN1 & Intracellular organelle transport \\
\hline SIGLEC1/CD169 & $\begin{array}{l}\text { Neuron glia interaction, plays role in phagocytosis; marker of } \\
\text { pathogenic phagocytosis in MS }\end{array}$ \\
\hline FAM175B & Regulates IFN pathway \\
\hline NAGLU & $\begin{array}{l}\text { Required for lysosomal degradtion of heparan suphate, leads } \\
\text { to neurodegneration }\end{array}$ \\
\hline UBXN4 & Invovled in ER protein degradation \\
\hline GRN & $\begin{array}{l}\text { Defeciency activates complement pathways and synaptic } \\
\text { prunning }\end{array}$ \\
\hline ITPP2 & $\begin{array}{l}\text { Component of the proteolytic cascade acting downstream of } \\
\text { the } 26 \mathrm{~S} \text { proteasome in the ubiquitin-proteasome pathway. } \\
\text { Release of anN-terminal tripeptide from a polypeptide. }\end{array}$ \\
\hline ITPA & $\begin{array}{l}\text { Deactivation leads to accumulation of ionosin triphosphate. } \\
\text { Mutated in IBD patients }\end{array}$ \\
\hline ISYNA1 & Modified by nitric oxide post LPS treatment \\
\hline FAM49B & Silencing leads to mitochondrial fission and ROS generation \\
\hline PSMB9 & Major component of immunoproteosome \\
\hline HSPA1B & $\begin{array}{l}\text { Chaperon involved in stress, KO mouse more vulnerable to } \\
\text { PD toxicant MPTP. Deletion causes MAPK activation in } \\
\text { cardiomyocytes }\end{array}$ \\
\hline FYN & $\begin{array}{l}\text { Our group have shown that Fyn phosphorylation leads to } \\
\text { inflammation in PD models }\end{array}$ \\
\hline HSPA1L & Involved in mitochondrial protein transport and folding \\
\hline BLNK & Regulates RET signaling \\
\hline ORC4 & Not found \\
\hline RHGAP18 & $\begin{array}{l}\text { Downregulation caues formation of stress fibers, } \\
\text { downregulated in LPS treated microglia }\end{array}$ \\
\hline MEMO1 & Involved in migration and microtubule assembly \\
\hline DNAH17 & Microtubule motor activity \\
\hline
\end{tabular}

in the PFC was seen in glial cells that predominantly had microglial morphology regardless of disease status. Double immunofluorescence studies of PGRN and microglial markers were confounded by lipofuscin-associated auto-fluorescence, limiting our ability to perform quantitative and microgliaspecific analyses. Overall, since Grn is highly expressed at the transcriptomic level in microglia in mammalian brain, our invivo studies show a general agreement that PGRN expression is indeed observed in microglia in human PD cases, especially in the pre-frontal cortex.
TABLE 3 | Concordance between differentially expressed genes in human PD and proteins in $\alpha$ Syn $_{\text {Agg }}$-treated microglia (related to Figure $\mathbf{4 C}$ ).

\begin{tabular}{ll}
\hline Protein & Role \\
\hline HIMGA2 & Driver of inflammation in liver toxicity induced by LPS \\
P4HA1 & Knockdown reduces prolifereration and migration of glioma stem cells \\
FRMD8 & Promotes inflammation and growth \\
STMN1 & Regulates transcription \\
FBX022 & Reduces inflammation by inhibition of Nfkb \\
STMN1 & Induces proliferation and is activated by phosphorylation \\
HPGD & Inhibits prostagladins and hence regulates inflammation \\
MAPRE3 & Regulates microtubule assembly and cellular polarization.
\end{tabular}

\section{$\alpha$ Syn Induced Mitochondrial Dysfunction in Microglial Cells}

Since our in vitro mouse microglia showed concordant dysregulation of mitochondrial proteins induced by $\alpha S_{y n} n_{\mathrm{Agg}}$, we performed Seahorse studies of mitochondrial stress in primary mouse microglia (Figures 6A,B). Though the role of mitochondrial dysfunction is well studied in neurons (53), the exact function of microglial mitochondrial dysfunction is still not well-understood. We have recently shown that mitochondrial dysfunction in microglia leads to inflammation by activation of NLRP3 inflammasome activation (31). Hence, to further validate that $\alpha$ Syn can induce mitochondrial damage in microglial cells, we performed seahorse mitostress test on primary mouse microglial cells, treated with $1 \mu \mathrm{M} \alpha \mathrm{Syn}_{\mathrm{Agg}}$ for $24 \mathrm{~h}$ to mirror our proteomic studies. $\alpha$ Syn altered mitochondrial dynamics in microglial cells as shown by changes in maximal respiration (Figure 6C), proton leak (Figure 6D), ATP production (Figure 6E) and basal respiration (Figure 6F). These confirmatory findings, together with our proteomics results, show that $\alpha$ Syn can cause mitochondrial dysfunction in microglial cells.

\section{DISCUSSION}

Neurodegenerative disorders including Alzheimer's disease and PD are characterized by chronic inflammation in the brain $(2,54,55)$. Hyperactivation of microglia and astroglia is a key pathophysiological hallmark of these neurodegenerative diseases $(55,56)$. GWAS have identified multiple immune related candidate genes which can presumably modify PD disease risk (57). $\alpha$ Syn $_{\mathrm{Agg}}$ is one of the major components of Lewy body and Lewy neurites. Various studies from our group and others have shown that $\alpha \operatorname{Syn}_{\mathrm{Agg}}$ activates microglial cells to induce the production of pro-inflammatory cytokines and chemokines $(25,32,58) \cdot \alpha \operatorname{Syn}_{\mathrm{Agg}}$ can bind to TLR-2 or CD-36 on microglial surface to activate the downstream pro-inflammatory signaling cascade (59).

Though neuroinflammation is a key pathological finding in PD, the mechanisms involved in aSyn-induced neuroinflammation are not well-defined, in part due to lack of relevant in vivo model systems. In this study we have 

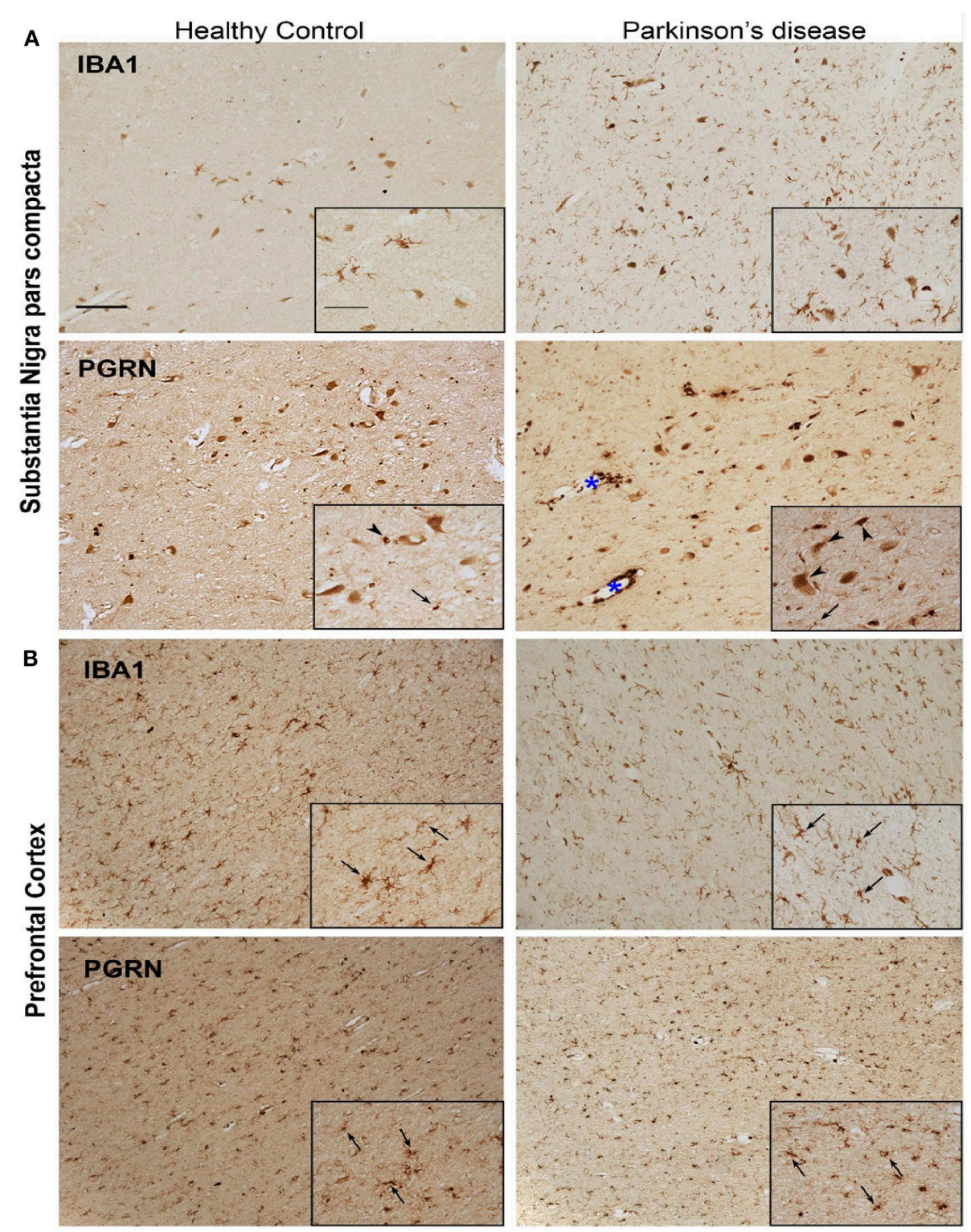

FIGURE 5 | Representative microphotographs of IBA1 and PGRN immunostained tissue in the region of the SNpc (A) and PFC (B) of a healthy control and PD patient. Presence of IBA1 + microglia significantly increased in the nigra of PD compared to healthy control, yet despite the abundant quantity of microglia, few PGRN-immunoreactive cells resemble microglia morphology (arrows) in the SNpc (A). Instead, PGRN is detected in neuromelanin cells or present as neuronal cell bodies (arrow heads) and in perivasculature spaces (blue asterisk). IBA1-immunoreactivity is similar in the PFC between healthy control and PD patient, and PGRN+ cells largely resemble microglial morphology (arrows) in both subjects (B). Scale bar $100 \mu \mathrm{m}$, inset $50 \mu \mathrm{m}$.

performed comprehensive analyses of microglial protein changes following $\alpha \mathrm{Syn}_{\mathrm{Agg}}$ treatment to define the key molecular changes and pathways that are activated or suppressed by $\alpha \operatorname{Syn}_{\mathrm{Agg}}$. Through GO analyses of differentially expressed proteins and by integrating our findings with existing microglial proteomes, we have identified several molecular pathways including Stat3 activation, decreased antigen presentation, increased RNA splicing and mitochondrial oxidative stress as predominant and unique effects of $\alpha$ Syn in microglia. The human disease relevance of our findings is further emphasized by identification of several PD GWAS risk genes within $\alpha$ Syn-regulated proteins. Specifically, we found that progranulin was downregulated both at the mRNA and protein level in mouse microglia in response to $\alpha$ Syn. Consistent with this finding, we observed that relative to the significant upregulation of IBA1+ cells in the SNpc of PD brains, where $\alpha$ Syn aggregates are common, the disease state does not result in greater levels of PGRN+ cells. No marked difference was found between PD and HC PFC in microglia PGRN expression, a brain region where $\alpha$ Syn aggregation is less common in PD. In addition, the reductions in Grn mRNA 


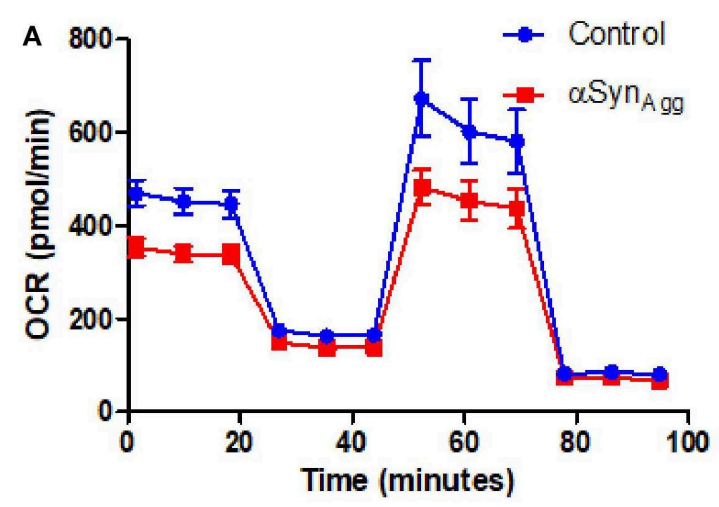

C

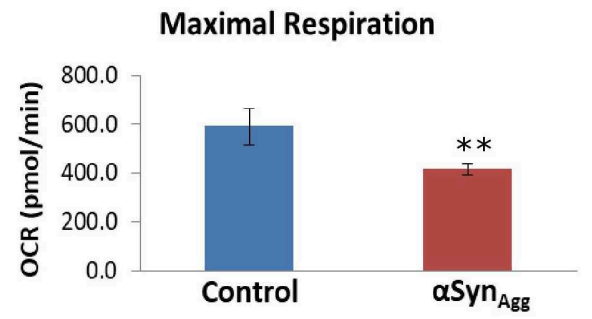

E

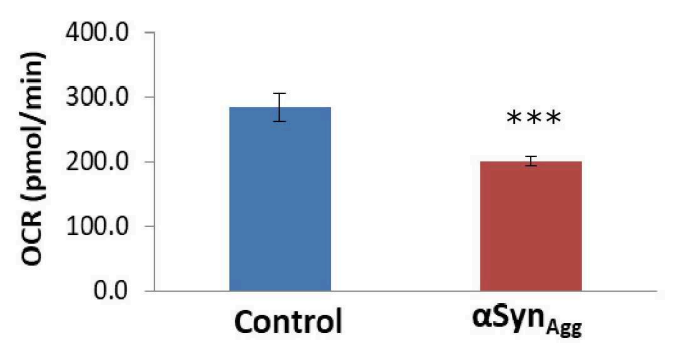

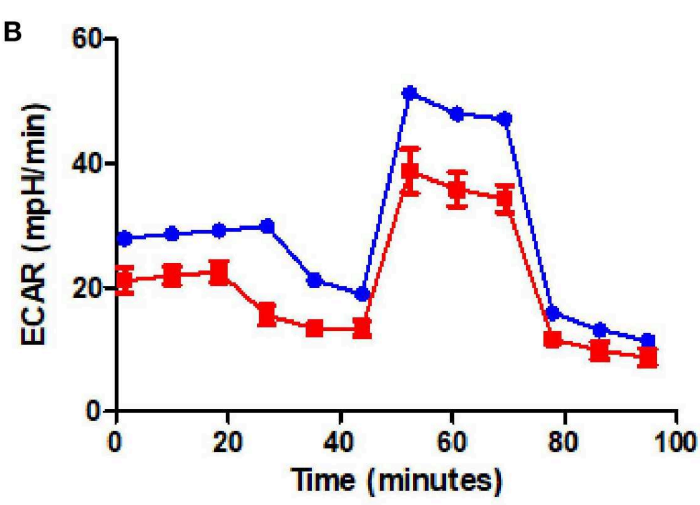

D

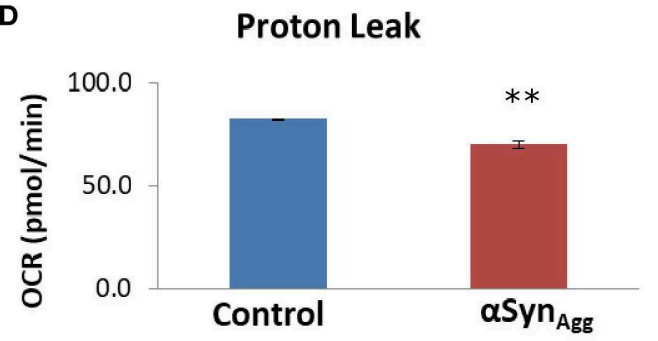

$\mathbf{F}$

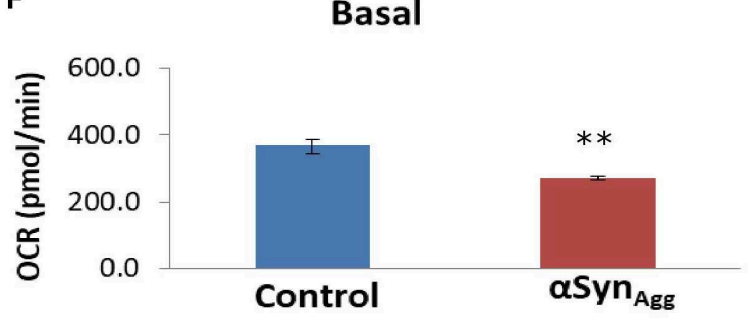

FIGURE 6 | $\alpha$ Syn induced mitochondrial dysfunction in microglial cells. Primary microglial cells were treated with $1 \mu \mathrm{M} \alpha$ Syn for $24 \mathrm{~h}$ and Seahorse Mitostress test was performed. (A) OCR and (B) ECR of primary microglial cells treated with $\alpha$ Syn. (C) Maximal respiration, (D) Proton leak, (E) ATP production, and (F) Basal respiration of primary microglial cells treated with $\alpha$ Syn. Data analyzed using student's $t$-test with $n=4$ for each group. ${ }^{\star \star} p<0.01,{ }^{\star \star \star}<0.005$.

and PGRN protein in PD may be further compounded by sequestration of PGRN into aggregates or inclusions evident in the PD SNpc in a manner analogous to what has been reported for other endo-lysosomal membrane proteins (LAMP1 and Rab5) accumulating at amyloid plaques (60).

The JAK stat pathway has been implicated in regulating inflammation and neurodegeneration in an $\alpha$ Synuclein adenoassociated virus model of PD pathogenesis (61). This study demonstrated that inhibiting JAK/STAT pathway using an inhibitor reduced MHC-II and inflammatory gene expression in microglia induced by aSynuclein. Further, Qin et al. demonstrated that JAK/STAT inhibitor reduced inflammatory chemokines and cytokines, infiltrating T-cells and microglial activation in rodent models of PD. Here, we demonstrate that $\alpha \operatorname{Syn}_{\text {Agg }}$ induced the upregulation of pro-inflammatory proteins and among these, the STAT3 signaling pathway was highly enriched in our proteomic analysis. We further validated our findings from proteomics using primary microglial cells and showed that $\alpha \mathrm{Syn}_{\mathrm{Agg}}$-induced upregulation of both total and phosphorylated STAT3. Interestingly, the effects on STAT3 were specific to the aggregate rather than monomeric form of $\alpha$ Syn emphasizing the profound pro-inflammatory effect of aggregated $\alpha$ Syn on microglia (Supplementary Figure 4). These findings also suggest that the STAT3 signaling pathway may be targeted to reduce $\alpha S_{S y} n_{A g g}$-induced inflammation in glial cells.

$\alpha$ Syn $_{\text {Agg }}$ can be taken up by microglial cells. Once internalized, $\alpha \operatorname{Syn}_{\text {Agg }}$ has been shown to bind to mitochondrial pore complex to block the TOM20 pore complex leading to mitochondrial 
dysfunction and apoptosis in neurons (62). Though the role of mitochondrial dysfunction in neurons is well-established in $\mathrm{PD}$, the role of glial mitochondrial dysfunction is not wellstudied. We have recently shown that mitochondrial dysfunction in glial cells can lead to an inflammatory response $(19,20)$. We also identified metabolic pathways that are altered post $\alpha \operatorname{Syn}_{\text {Agg }}$ treatment further suggesting the probable role of mitochondria in regulating inflammation. Furthermore, we validated using seahorse metabolic flux assay that $\alpha S_{\mathrm{Agg}}$ leads to mitochondrial dysfunction.

Another specific signature of $\alpha \mathrm{Syn}_{\mathrm{Agg}}$-induced changes in microglial cells is modulation in expression of RNA binding proteins. Our GO analysis revealed an enrichment of RNA binding proteins induced by $\alpha \operatorname{Syn}_{\mathrm{Agg}}$ and not LPS. Though $\alpha$ Syn is classically considered to be a synaptic protein, recent studies have shown that $\alpha$ Syn can localize to the nucleus and regulate histone modification and neurotoxicity $(63,64)$. Out of the RNA binding proteins which are upregulated, of interest is Caspase8. We have recently shown that $\alpha \operatorname{Syn}_{\mathrm{Agg}}$ leads to NLRP3 inflammasome activation through Fyn signaling (28) in microglial cells leading to IL-1 $\beta$ release although inhibition of NLRP3 inflammasome did not completely attenuate IL-1 $\beta$ release, presumably indicating NLRP3 inflammasomeindependent release of IL-1 $\beta$. Caspase 8 has been shown to regulate IL-1 $\beta$ secretion independent of inflammasome activation depending on the stimulus $(65,66)$. Further studies focused $\alpha S_{\text {Syn }}$ Agg -induced IL- $1 \beta$ release and Caspase- 8 dependent cleavage of IL-1 $\beta$ may identify a novel mechanism that drives microglia-mediated neuroinflammation. Further studies are required to understand the interaction of these RNA-binding proteins and $\alpha \operatorname{Syn}_{\mathrm{Agg}}$ as well as the exact mechanism that regulates this interaction.

Though GWAS have been able to identify genetic risk factors of PD development, most of the studies relating GWAS hits to their functions have been limited to neurons. In this study we compare GWAS results with microglial proteomics, raising the possibility that some of the risk of PD may be mediated through microglia. The comparison between GWAS studies and our proteomic study identified progranulin as a potential candidate protein that is regulated by $\alpha S_{\mathrm{Syg}}$. We have recently shown that Fyn, a hit in our proteomic data, is modified in PD patients and plays a role in inflammasome activation (28). Downregulation of progranulin in microglial cells has been shown to induce synaptic pruning through the complement pathway (67). Progranulin has further been shown to be a chemoattractant for microglia and to regulate the endosomal pathways of microglia, which were also altered in our proteomic study (68). We further validated this result in primary microglial cells using qPCR. Furthermore, immunohistochemistry in post mortem brains from PD patients and age matched controls showed PGRN expression in both neurons and microglia; but reduced PGRN immunoreactivity in cells of glial morphology in PD SNpc compared to PD PFC. These results suggest downregulation of PGRN in brain regions with $\alpha$ Syn aggregates/inclusions (60). Interestingly, a recent transcriptomic analysis using PGRN knockout mice have shown that granulin knockdown enhances the microglial neurodegenerative phenotype (MGnD) (69).
Further mechanistic studies in animal models and cell culture model of PD to identify the role of PGRN in regulating microglial inflammation in PD is warranted.

In conclusion, we have employed a comprehensive proteomics approach integrated with experimental validation to identify novel molecular mechanisms of $\alpha S_{\mathrm{Syn}} \mathrm{Agg}_{\text {-induced }}$ neuroinflammation. In mouse microglia, aSynuclein uniquely increases expression of RNA binding proteins suggesting augmented RNA processing and splicing in addition to mitochondrial oxidative stress. We also provide evidence for decreased microglial progranulin as a novel disease mechanism in $\mathrm{PD}$, implicating lysosomal dysfunction and autophagy in $\mathrm{PD}$ pathogenesis. A limitation of our study is the lack of mechanistic understanding of neuroinflammation induced by $\alpha$-synuclein. Further, different synucleinopathies have different forms of aggregates, which may have different levels of toxicity. Future studies looking into the signatures of different form of aggregates is warranted. Our comprehensive quantitative proteomic dataset represents a valuable resource that can guide future neuroscience research to better understand $\alpha$ Syn-mediated neurodegenerative diseases. Future studies demonstrating the mechanistic relationship between some of the proteins identified in this study is necessary to understand the etiology of microglial activation in PD.

\section{DATA AVAILABILITY STATEMENT}

The raw data supporting the conclusions of this study will be made available by the authors upon reasonable request. Data are available via ProteomeXchange with identifier PXD013691.

\section{ETHICS STATEMENT}

The animal study was reviewed and approved by Emory IACUC.

\section{AUTHOR CONTRIBUTIONS}

SS, ED, AK, and SR conceptualized the study, SS, ED, AO, SAR, TG, DO, VJ, HX, EM, NS, and MH performed the experiments. SS, ED, SR, MT, NS, TK, and AK analyzed data and edited the manuscript.

\section{FUNDING}

This work was supported by Emory Alzheimer's Disease Research Center Grant P50 AG025688, Alzheimer's Association (SR \#37102), NINDS (K08-NS099474-1) and Emory Neuroscience NINDS Core facilities (P30 NS055077) to SR; NINDS (NS100090) and NIEHS (ES026892) to AK; National Institutes of Health (NIH) Grants (R01NS093362, R01NS105971), a New Vision Award (Donors Cure Foundation), an Emory Alzheimer's Disease Center Pilot Grant P50AG025688, the Alzheimer's Drug Discovery Foundation, the Association for Frontotemporal Degeneration (ADDF/AFTD), and the Bluefield Project to Cure Frontotemporal Dementia to TK; National Institutes of Health (NIH) fellowship (Training in Translational Research 
in Neurology, 2T32NS007480-16), NIH Udall pilot grant (1P50NS098685) and NIH Yerkes Pilot grant (P51 OD011132) to VJ National Institutes of Health (NIH) Grants (5R01NS092122, 1RF1AG051514, 1RF1AG057247), the ADDF/AFTD, and the Michael J. Fox Foundation for Parkinson's Research to MT.

\section{REFERENCES}

1. Cunningham C. Microglia and neurodegeneration: the role of systemic inflammation. Glia. (2013) 61:71-90. doi: 10.1002/glia.22350

2. Block ML, Zecca L, Hong JS. Microglia-mediated neurotoxicity: uncovering the molecular mechanisms. Nat Rev Neurosci. (2007) 8:57-69. doi: $10.1038 / \mathrm{nrn} 2038$

3. Langley M, Ghosh A, Charli A, Sarkar S, Ay M, Luo J, et al. Mito-apocynin prevents mitochondrial dysfunction, microglial activation, oxidative damage, and progressive neurodegeneration in mitopark transgenic mice. Antioxid Redox Signal. (2017). 27:1048-1066. doi: 10.1089/ars.2016.6905

4. Whitton PS. Inflammation as a causative factor in the aetiology of Parkinson's disease. Br J Pharmacol. (2007) 150:963-76. doi: 10.1038/sj.bjp.0707167

5. Hirsch EC, Hunot S. Neuroinflammation in Parkinson's disease: a target for neuroprotection? Lancet Neurol. (2009) 8:382-97. doi: 10.1016/S1474-4422(09)70062-6

6. Tansey MG, Goldberg MS. Neuroinflammation in Parkinson's disease: its role in neuronal death and implications for therapeutic intervention. Neurobiol Dis. (2010) 37:510-8. doi: 10.1016/j.nbd.2009.11.004

7. Perry VH. Innate inflammation in Parkinson's disease. Cold Spring Harb Perspect Med. (2012) 2:a009373. doi: 10.1101/cshperspect.a009373

8. Wang Q, Liu Y, Zhou J. Neuroinflammation in Parkinson's disease and its potential as therapeutic target. Transl Neurodegener. (2015) 4:19. doi: 10.1186/s40035-015-0042-0

9. Nagatsu T, Mogi M, Ichinose H, Togari A. Cytokines in Parkinson's disease. J Neural Transm Suppl. (2000) 143-51. doi: 10.1007/978-3-7091-6284-2_12

10. Kosloski LM, Kosmacek EA, Olson KE, Mosley RL, Gendelman HE. GMCSF induces neuroprotective and anti-inflammatory responses in 1-methyl-4phenyl-1,2,3,6-tetrahydropyridine intoxicated mice. J Neuroimmunol. (2013) 265:1-10. doi: 10.1016/j.jneuroim.2013.10.009

11. Panicker N, Saminathan H, Jin H, Neal M, Harischandra DS, Gordon R, et al. Fyn Kinase Regulates Microglial Neuroinflammatory Responses in Cell Culture and Animal Models of Parkinson's Disease. J Neurosci. (2015) 35:10058-77. doi: 10.1523/JNEUROSCI.0302-15.2015

12. Ghosh A, Langley MR, Harischandra DS, Neal ML, Jin H, Anantharam $\mathrm{V}$, et al. Mitoapocynin treatment protects against neuroinflammation and dopaminergic neurodegeneration in a preclinical animal model of Parkinson's Disease. J Neuroimmune Pharmacol. (2016) 11:259-78. doi: 10.1007/s11481-016-9650-4

13. Martin HL, Santoro M, Mustafa S, Riedel G, Forrester JV, Teismann P. Evidence for a role of adaptive immune response in the disease pathogenesis of the MPTP mouse model of Parkinson's disease. Glia. (2016) 64:386-95. doi: 10.1002 /glia.22935

14. Gagliano SA, Pouget JG, Hardy J, Knight J, Barnes MR, Ryten M, et al. Genomics implicates adaptive and innate immunity in Alzheimer's and Parkinson's diseases. Ann Clin Transl Neurol. (2016) 3:924-33. doi: 10.1002/acn3.369

15. Seyfried NT, Dammer EB, Swarup V, Nandakumar D, Duong DM, Yin L, et al. A multi-network approach identifies protein-specific co-expression in asymptomatic and symptomatic Alzheimer's Disease. Cell Syst. (2017). 4:60-72 e64. doi: 10.1016/j.cels.2016.11.006

16. Rees K, Stowe R, Patel S, Ives N, Breen K, Clarke CE, et al. Non-steroidal anti-inflammatory drugs as disease-modifying agents for Parkinson's disease: evidence from observational studies. Cochrane Database Syst Rev. (2011). CD008454. doi: 10.1002/14651858.CD008454.pub2

17. Paolicelli RC, Bolasco G, Pagani F, Maggi L, Scianni M, Panzanelli P, et al. Synaptic pruning by microglia is necessary for normal brain development. Science. (2011) 333:1456-8. doi: 10.1126/science.1202529

18. Lawana V, Singh N, Sarkar S, Charli A, Jin H, Anantharam V, et al. Involvement of c-Abl kinase in microglial activation of NLRP3 inflammasome

\section{SUPPLEMENTARY MATERIAL}

The Supplementary Material for this article can be found online at: https://www.frontiersin.org/articles/10.3389/fimmu. 2020.00033/full\#supplementary-material

and impairment in autolysosomal system. J Neuroimmune Pharmacol. (2017) 12:624-60. doi: 10.1007/s11481-017-9746-5

19. Sarkar S, Malovic E, Harischandra DS, Ngwa HA, Ghosh A, Hogan C, et al. Manganese exposure induces neuroinflammation by impairing mitochondrial dynamics in astrocytes. Neurotoxicology. (2018) 64:204-18. doi: 10.1016/j.neuro.2017.05.009

20. Sarkar S, Malovic E, Harishchandra DS, Ghaisas S, Panicker N, Charli A, et al. Mitochondrial impairment in microglia amplifies NLRP3 inflammasome proinflammatory signaling in cell culture and animal models of Parkinson's disease. NPJ Parkinsons Dis. (2017) 3:30. doi: 10.1038/s41531-017-0032-2

21. Mosley RL, Hutter-Saunders JA, Stone DK, Gendelman HE. Inflammation and adaptive immunity in Parkinson's disease. Cold Spring Harb Perspect Med. (2012) 2:a009381. doi: 10.1101/cshperspect.a009381

22. Zhang W, Wang T, Pei Z, Miller DS, Wu X, Block ML, et al. Aggregated alpha-synuclein activates microglia: a process leading to disease progression in Parkinson's disease. FASEB J. (2005) 19:533-42. doi: 10.1096/fj.04-2751com

23. Beyer K, Domingo-Sabat M, Ariza A. Molecular pathology of Lewy body diseases. Int J Mol Sci. (2009) 10:724-45. doi: 10.3390/ijms10030724

24. Zhang W, Dallas S, Zhang D, Guo JP, Pang H, Wilson B, et al. Microglial PHOX and Mac-1 are essential to the enhanced dopaminergic neurodegeneration elicited by A30P and A53T mutant alpha-synuclein. Glia. (2007) 55:1178-88. doi: 10.1002/glia.20532

25. Gordon R, Singh N, Lawana V, Ghosh A, Harischandra DS, Jin H, et al. Protein kinase Cdelta upregulation in microglia drives neuroinflammatory responses and dopaminergic neurodegeneration in experimental models of Parkinson's disease. Neurobiol Dis. (2016) 93:96-114. doi: 10.1016/j.nbd.2016.04.008

26. Su X, Maguire-Zeiss KA, Giuliano R, Prifti L, Venkatesh K, Federoff HJ. Synuclein activates microglia in a model of Parkinson's disease. Neurobiol Aging. (2008) 29:1690-701. doi: 10.1016/j.neurobiolaging.2007.04.006

27. Fellner L, Irschick R, Schanda K, Reindl M, Klimaschewski L, Poewe W, et al. Toll-like receptor 4 is required for alpha-synuclein dependent activation of microglia and astroglia. Glia. (2013) 61:349-60. doi: 10.1002/glia.22437

28. Panicker N, Sarkar S, Harischandra DS, Neal M, Kam TI, Jin H, et al. Fyn kinase regulates misfolded alpha-synuclein uptake and NLRP3 inflammasome activation in microglia. J Exp Med. (2019) 216:1411-30. doi: 10.1084/jem.20182191

29. Sarkar S, Malovic E, Plante B, Zenitsky G, Jin H, Anantharam V, et al. Rapid and refined CD11b magnetic isolation of primary microglia with enhanced purity and versatility. J Vis Exp. (2017). doi: 10.3791/55364

30. Halle A, Hornung V, Petzold GC, Stewart CR, Monks BG, Reinheckel T, et al. The NALP3 inflammasome is involved in the innate immune response to amyloid-beta. Nat Immunol. (2008) 9:857-65. doi: 10.1038/ni.1636

31. Sarkar S, Rokad D, Malovic E, Luo J, Harischandra DS, Jin H, et al. Manganese activates NLRP3 inflammasome signaling and propagates exosomal release of ASC in microglial cells. Sci Signal. (2019) 12:eaat9900. doi: 10.1126/scisignal.aat9900

32. Sarkar S, Malovic E, Sarda D, Lawana V, Rokad D, Jin H, et al. Characterization and comparative analysis of a new mouse microglial cell model for studying neuroinflammatory mechanisms during neurotoxic insults. Neurotoxicology. (2018) 67:129-40. doi: 10.1016/j.neuro.2018.05.002

33. Harischandra DS, Rokad D, Neal ML, Ghaisas S, Manne S, Sarkar $\mathrm{S}$, et al. Manganese promotes the aggregation and prion-like cell-tocell exosomal transmission of alpha-synuclein. Sci Signal. (2019) 12. doi: 10.1126/scisignal.aau4543

34. Giasson BI, Uryu K, Trojanowski JQ, Lee VM. Mutant and wild type human alpha-synucleins assemble into elongated filaments with distinct morphologies in vitro. J Biol Chem. (1999) 274:7619-22. doi: $10.1074 /$ jbc. 274.12 .7619

35. Narhi L, Wood SJ, Steavenson S, Jiang Y, Wu GM, Anafi D, et al. Both familial Parkinson's disease mutations accelerate alpha-synuclein 
aggregation. J Biol Chem. (1999) 274:9843-6. doi: 10.1074/jbc.274.1 4.9843

36. Luk KC, Kehm V, Carroll J, Zhang B, O’brien P, Trojanowski JQ, et al. Pathological alpha-synuclein transmission initiates Parkinson-like neurodegeneration in nontransgenic mice. Science. (2012) 338:949-53. doi: $10.1126 /$ science.1227157

37. Rangaraju S, Raza SA, Pennati A, Deng Q, Dammer EB, Duong D, et al. A systems pharmacology-based approach to identify novel Kv1.3 channeldependent mechanisms in microglial activation. J Neuroinflammation. (2017) 14:128. doi: 10.1186/s12974-017-0906-6

38. Gao, T, Jernigan, J, Raza, SA, Dammer EB, Xiao H, Seyfried NT, et al. Transcriptional regulation of homeostatic and disease-associatedmicroglial genes by IRF1, LXR $\beta$, and CEBP $\alpha$. Glia. (2019) 67:1958-75. doi: 10.1002 /glia. 23678

39. Gordon R, Neal ML, Luo J, Langley MR, Harischandra DS, Panicker N, et al. Prokineticin-2 upregulation during neuronal injury mediates a compensatory protective response against dopaminergic neuronal degeneration. Nat Commun. (2016) 7:12932. doi: 10.1038/ncomms12932

40. Spandidos A, Wang X, Wang H, Seed B. PrimerBank: a resource of human and mouse PCR primer pairs for gene expression detection and quantification. Nucleic Acids Res. (2010) 38:D792-9. doi: 10.1093/nar/gkp1005

41. Neal M, Luo J, Harischandra DS, Gordon R, Sarkar S, Jin H, et al. Prokineticin2 promotes chemotaxis and alternative A2 reactivity of astrocytes. Glia. (2018) 66:2137-57. doi: 10.1002/glia.23467

42. Singh N, Lawana V, Luo J, Phong P, Abdalla A, Palanisamy B, et al. Organophosphate pesticide chlorpyrifos impairs STAT1 signaling to induce dopaminergic neurotoxicity: Implications for mitochondria mediated oxidative stress signaling events. Neurobiol Dis. (2018) 117:82-113. doi: 10.1016/j.nbd.2018.05.019

43. Tyanova S, Mann M, Cox J. MaxQuant for in-depth analysis of large SILAC datasets. Methods Mol Biol. (2014) 1188:351-64. doi: 10.1007/978-1-4939-1142-4_24

44. Dai J, Johnson ECB, Dammer EB, Duong DM, Gearing M, Lah JJ, et al. Effects of APOE genotype on brain proteomic network and cell type changes in Alzheimer's Disease. Front Mol Neurosci. (2018) 11:454. doi: 10.3389/fnmol.2018.00454

45. Lesnick TG, Papapetropoulos S, Mash DC, Ffrench-Mullen J, Shehadeh $\mathrm{L}$, De Andrade $\mathrm{M}$, et al. A genomic pathway approach to a complex disease: axon guidance and Parkinson disease. PLoS Genet. (2007) 3:e98. doi: 10.1371/journal.pgen.0030098

46. Tyanova S, Temu T, Carlson A, Sinitcyn P, Mann M, Cox J. Visualization of LC-MS/MS proteomics data in MaxQuant. Proteomics. (2015) 15:1453-6. doi: 10.1002/pmic.201400449

47. Tyanova S, Temu T, Sinitcyn P, Carlson A, Hein MY, Geiger T, et al. The Perseus computational platform for comprehensive analysis of (prote)omics data. Nat Methods. (2016) 13:731-40. doi: 10.1038/nmeth.3901

48. Beraud D, Maguire-Zeiss KA. Misfolded alpha-synuclein and Toll-like receptors: therapeutic targets for Parkinson's disease. Parkinsonism Relat Disord. (2012) 18 (Suppl. 1):S17-20. doi: 10.1016/S1353-8020(11)70008-6

49. Daniele SG, Beraud D, Davenport C, Cheng K, Yin H, Maguire-Zeiss KA. Activation of MyD88-dependent TLR1/2 signaling by misfolded alphasynuclein, a protein linked to neurodegenerative disorders. Sci Signal. (2015) 8:ra45. doi: 10.1126/scisignal.2005965

50. Sharma K, Schmitt S, Bergner CG, Tyanova S, Kannaiyan N, Manrique-Hoyos $\mathrm{N}$, et al. Cell type- and brain region-resolved mouse brain proteome. Nat Neurosci. (2015) 18:1819-31. doi: 10.1038/nn.4160

51. Zhang F, Guo Z, Zhong H, Wang S, Yang W, Liu Y, et al. RNA-Seq-based transcriptome analysis of aflatoxigenic Aspergillus flavus in response to water activity. Toxins. (2014) 6:3187-207. doi: 10.3390/toxins6113187

52. Kam TI, Mao X, Park H, Chou SC, Karuppagounder SS, Umanah GE, et al. Poly(ADP-ribose) drives pathologic alpha-synuclein neurodegeneration in Parkinson's disease. Science. (2018) 362:eaat8407. doi: 10.1126/science.aat8407

53. Ordonez DG, Lee MK, Feany MB. alpha-synuclein induces mitochondrial dysfunction through spectrin and the actin cytoskeleton. Neuron. (2018) 97:108-124 e106. doi: 10.1016/j.neuron.2017.11.036

54. Guo H, Callaway JB, Ting JP. Inflammasomes: mechanism of action, role in disease, and therapeutics. Nat Med. (2015) 21:677-87. doi: 10.1038/nm.3893

55. Freeman LC, Ting JP. The pathogenic role of the inflammasome in neurodegenerative diseases. J Neurochem. (2016) 136 (Suppl. 1):29-38. doi: $10.1111 /$ jnc. 13217
56. Barker BR, Taxman DJ, Ting JP. Cross-regulation between the IL-1beta/IL18 processing inflammasome and other inflammatory cytokines. Curr Opin Immunol. (2011) 23:591-7. doi: 10.1016/j.coi.2011.07.005

57. Chang D, Nalls MA, Hallgrimsdottir IB, Hunkapiller J, Van Der Brug M, Cai F, et al. A meta-analysis of genome-wide association studies identifies 17 new Parkinson's disease risk loci. Nat Genet. (2017) 49:1511-6. doi: 10.1038/ng.3955

58. Codolo G, Plotegher N, Pozzobon T, Brucale M, Tessari I, Bubacco $\mathrm{L}$, et al. Triggering of inflammasome by aggregated alpha-synuclein, an inflammatory response in synucleinopathies. PLoS ONE. (2013) 8:e55375. doi: 10.1371/journal.pone.0055375

59. Beraud D, Twomey M, Bloom B, Mittereder A, Ton V, Neitzke K, et al. alphasynuclein alters toll-like receptor expression. Front Neurosci. (2011) 5:80. doi: 10.3389/fnins.2011.00080

60. Gowrishankar S, Yuan P, Wu Y, Schrag M, Paradise S, Grutzendler J, et al. Massive accumulation of luminal protease-deficient axonal lysosomes at Alzheimer's disease amyloid plaques. Proc Natl Acad Sci USA. (2015) 112:E3699-708. doi: 10.1073/pnas.1510329112

61. Qin H, Buckley JA, Li X, Liu Y, Fox TH III, Meares GP, Yu H, et al. Inhibition of the JAK/STAT pathway protects against alphasynuclein-induced neuroinflammation and dopaminergic neurodegeneration. JNeurosci. (2016) 36:5144-59. doi: 10.1523/JNEUROSCI.4658-15.2016

62. Di Maio R, Barrett PJ, Hoffman EK, Barrett CW, Zharikov A, Borah A, et al. alpha-Synuclein binds to TOM20 and inhibits mitochondrial protein import in Parkinson's disease. Sci Transl Med. (2016) 8:342ra378. doi: 10.1126/scitranslmed.aaf3634

63. Kontopoulos E, Parvin JD, Feany MB. Alpha-synuclein acts in the nucleus to inhibit histone acetylation and promote neurotoxicity. Hum Mol Genet. (2006) 15:3012-23. doi: 10.1093/hmg/ddl243

64. Ma KL, Song LK, Yuan YH, Zhang Y, Han N, Gao K, et al. The nuclear accumulation of alpha-synuclein is mediated by importin alpha and promotes neurotoxicity by accelerating the cell cycle. Neuropharmacology. (2014) 82:132-42. doi: 10.1016/j.neuropharm.2013.07.035

65. Shenderov K, Riteau N, Yip R, Mayer-Barber KD, Oland S, Hieny S, et al. Cutting edge: Endoplasmic reticulum stress licenses macrophages to produce mature IL-1beta in response to TLR4 stimulation through a caspase-8- and TRIF-dependent pathway. J Immunol. (2014) 192:2029-33. doi: 10.4049/jimmunol.1302549

66. Gurung P, Kanneganti TD. Novel roles for caspase- 8 in IL-1beta and inflammasome regulation. Am J Pathol. (2015) 185:17-25. doi: 10.1016/j.ajpath.2014.08.025

67. Lui H, Zhang J, Makinson SR, Cahill MK, Kelley KW, Huang HY, et al. Progranulin deficiency promotes circuit-specific synaptic pruning by microglia via complement activation. Cell. (2016) 165:921-35. doi: 10.1016/j.cell.2016.04.001

68. Pickford F, Marcus J, Camargo LM, Xiao Q, Graham D, Mo JR, et al. Progranulin is a chemoattractant for microglia and stimulates their endocytic activity. Am J Pathol. (2011) 178:284-95. doi: 10.1016/j.ajpath.2010.11.002

69. Gotzl JK, Brendel M, Werner G, Parhizkar S, Sebastian Monasor L, Kleinberger G, et al. Opposite microglial activation stages upon loss of PGRN or TREM2 result in reduced cerebral glucose metabolism. EMBO Mol Med. (2019) 11:e9711. doi: 10.15252/emmm.201809711

Conflict of Interest: Patent pending related to this work entitled "Methods to treat neurodegeneration with granulins" to TK. AK is a shareholder of PK Biosciences Corporation (Ames, IA), which is interested in identifying novel biomarkers and potential therapeutic targets for PD.

The remaining authors declare that the research was conducted in the absence of any commercial or financial relationships that could be construed as a potential conflict of interest.

Copyright (C) 2020 Sarkar, Dammer, Malovic, Olsen, Raza, Gao, Xiao, Oliver, Duong, Joers, Seyfried, Huang, Kukar, Tansey, Kanthasamy and Rangaraju. This is an openaccess article distributed under the terms of the Creative Commons Attribution License (CC BY). The use, distribution or reproduction in other forums is permitted, provided the original author(s) and the copyright owner(s) are credited and that the original publication in this journal is cited, in accordance with accepted academic practice. No use, distribution or reproduction is permitted which does not comply with these terms. 